OPEN ACCESS

Edited by:

Peng Xia,

Life Sciences Institute Zhejiang University, China

Reviewed by: Sai Luo,

First hospital of Harbin Medical University, China

Lijun Hao,

First Affiliated Hospital of Harbin Medical University, China

Chenggang $Y_{i}$

Fourth Military Medical University,

China

*Correspondence: Jianhua Gao

doctorgaojianhua@outlook.com

Specialty section:

This article was submitted to Morphogenesis and Patterning, a section of the journal Frontiers in Cell and Developmental

Biology

Received: 30 August 2021 Accepted: 16 November 2021 Published: 16 December 2021

Citation:

Bi X, Li Y, Dong Z, Zhao J, Wu W, Zou J, Guo L, Lu F and Gao J (2021) Recent Developments in Extracellular Matrix Remodeling for Fat Grafting. Front. Cell Dev. Biol. 9:767362. doi: 10.3389/fcell.2021.767362

\section{Recent Developments in Extracellular Matrix Remodeling for Fat Grafting}

\author{
Xin Bi, Ye Li, Ziqing Dong, Jing Zhao, Weizi Wu, Jialiang Zou, Lingling Guo, Feng Lu and \\ Jianhua Gao*
}

Department of Plastic and Cosmetic Surgery, Nanfang Hospital, Southern Medical University, Guangzhou, China

Remodeling of the extracellular matrix (ECM), which provides structural and biochemical support for surrounding cells, is vital for adipose tissue regeneration after autologous fat grafting. Rapid and high-quality ECM remodeling can improve the retention rate after fat grafting by promoting neovascularization, regulating stem cells differentiation, and suppressing chronic inflammation. The degradation and deposition of ECM are regulated by various factors, including hypoxia, blood supply, inflammation, and stem cells. By contrast, ECM remodeling alters these regulatory factors, resulting in a dynamic relationship between them. Although researchers have attempted to identify the cellular sources of factors associated with tissue regeneration and regulation of the microenvironment, the factors and mechanisms that affect adipose tissue ECM remodeling remain incompletely understood. This review describes the process of adipose ECM remodeling after grafting and summarizes the factors that affect ECM reconstruction. Also, this review provides an overview of the clinical methods to avoid poor ECM remodeling. These findings may provide new ideas for improving the retention of adipose tissue after fat transplantation.

\footnotetext{
Keywords: Adipose-derived stem cells (ASCs), extracellular matrix (ECM), fat transplantation, angiogenesis, hypoxia, inflammatory cells, macrophage
}

\section{INTRODUCTION}

Autologous fat grafting, which is widely used to augment volume and restore contour during softtissue reconstruction (Geeroms et al., 2019), has multiple advantages, including being minimally invasive, readily available, and inexpensive (Spear et al., 2016). Moreover, autologous fat can be easily harvested, and grafting can be performed multiple times, enabling its frequent use for filling and reshaping contour anomalies during both breast reconstruction and aesthetic operations (Ruan et al., 2019). Although the retention of grafted fat has become more predictable, it remains less than ideal (Mineda et al., 2014; Yu et al., 2015), requiring an in-depth understanding of fat regeneration after grafting and the development of various techniques to assist fat transfer (Cheriyan et al., 2014; Khouri and Khouri, 2017). The mechanism underlying the retention of transplanted adipose tissue is thought to involve a balance between successful (regeneration) and unsuccessful (cicatrization) tissue remodeling (Yoshimura et al., 2011). The morphogenesis of adipose tissue results from a selforganization process principally driven by simple mechanical interactions between adipocytes and the adipose extracellular matrix (ECM), with regeneration after injury involving the same mechanisms as regeneration after grafting (Peurichard et al., 2019). During the entire process of fat tissue regeneration, adipose ECM not only undergoes dynamic remodeling but also provides three-dimensional scaffolds for various types of cells and plays a pivotal role in optimizing outcomes, especially during the period of adipogenesis and angiogenesis (Kato et al., 2014). Therefore, 
improved understanding of the components, sources, and functions of adipose ECM, and optimizing the conditions affecting these factors, may facilitate the development of clinical strategies to improve the long-term retention of engrafted fat (Strong et al., 2015). This review focuses on the relationship between ECM remodeling and the microenvironment, a relatively neglected phenomenon during ECM reconstruction after fat grafting. This review also provides an overview of the potential consequence(s) of fat grafting and discusses its clinical applications.

\section{WHAT HAPPENS IN THE ADIPOSE EXTRACELLULAR MATRIX DURING FAT GRAFTING? \\ 2.1 Adipose Extracellular Matrix Composition}

Adipose ECM is comprised of complex structural and functional proteins, including collagen types I-VII, XVIII; non-collagenous proteins such as osteopontin, hyaluronan, and thrombospondin; and various types of adhesion proteins, such as fibronectin, laminin, proteoglycans, and elastins (Alkhouli et al., 2013; Aikio et al., 2014; Saunders et al., 2015; McKee et al., 2019).

Collagen, primarily collagen types I, III, IV, VI, and XVIII, are the most abundant proteins in the pericellular basement membrane and interstitial fibers of adipose tissue (Nakajima et al., 2002; Mariman and Wang, 2010; Mori et al., 2014; Liu et al., 2020). Type I collagen provides the main complex framework needed to maintain the structure and function of mesenchymal tissue (Liu X. et al., 2018). Type IV collagen, which is located below the vascular endothelial cell layer and acts as the basement membrane of the adipocyte region, provides binding sites for bioactive molecules, regulates cell behavior, and plays other important roles as a structural and functional protein (Streuli, 1999; Brown et al., 2011). Type VI collagen, which consists of three subunits, $\alpha 1, \alpha 2$, and $\alpha 3$, necessary for stable protein formation, provides a structural framework for adipose tissue formation (Theocharidis et al., 2016). Type VI collagen may also act as a fibrotic component that restricts adipose tissue expandability (Kokai et al., 2019). Studies in collagen VI knockout mice have shown that in the presence of expanding adipocytes, restricted ECM, mainly collagen VI, resulted in inflammation, hypoxia, and insulin resistance (Lawler et al., 2016). In addition, elimination of the increased collagen VI in adipose tissue under conditions of obesity resulted in healthier adipocytes (Sorisky et al., 2013). Type XVIII collagen is a ubiquitously expressed and structurally complex basement membrane proteoglycan, which supports pre-adipocyte differentiation and maintains the differentiation state of adipocytes (Aikio et al., 2014; Petäistö et al., 2020).

In addition to collagen, fibronectin and laminin participate in forming networks and provide attachment points for integrins anchored in the adipocyte membrane (Pope et al., 2016). Fibronectin is a ubiquitous and abundant adipose ECM protein, and a constituent of the primary mechanical structural fiber in adipose tissue (Lee et al., 2013; Zhang et al.,
2020). Fibronectin has been shown to enhance cell adhesion, proliferation, and migration, as well as stem cell differentiation, including adipose conversion during adipose tissue development (Lee et al., 2013; Zhang et al., 2020). Laminin is a major component of the basement membrane, along with collagen I and collagen IV, spreading tightly over adipocytes (Vaicik et al., 2014; Zhang et al., 2020).

\subsection{Adipose Extracellular Matrix Remodeling Process After Fat Grafting}

Throughout the entire process of fat grafting, the physiological state of fat tissue is disrupted, and the ECM goes through a program involving its degradation, synthesis, and deposition. Significant changes in the ECM alter the physiological functions of the encapsulated cells, including stem cells, mature adipocytes, endothelial cells, and fibroblasts, ultimately affecting the retention rates of fat grafts (Cai et al., 2017; Zhang et al., 2020).

Specifically, liposuction at the donor site disrupts the integrity of adipose tissue, with ECM fibers cut into small pieces, and some mature adipocytes and partly regeneration-related cells detaching from the highly complex framework of the ECM (Sun et al., 2013; Khouri et al., 2014a). The lipoaspirates injected into the recipient area subsequently experience severe ischemia and hypoxia. Local hemorrhage at the injured recipient tissue activates platelet cascade reactions, resulting in the release from activated platelets of platelet-derived growth factor (PDGF), epidermal growth factor (EGF), and transforming growth factor- $\beta$ (TGF$\beta$ ) (Aiba-Kojima et al., 2007). The surviving adipocytes are covered by platelets, which rapidly coagulate, forming a clot at the injection site within a few hours. The thin layers of fibers (fragile collagen) secreted by platelets form a loose connection between adipose lobules and each other within 1 day (Cai et al., 2017). Simultaneously, basic fibroblast growth factor (bFGF), tumor necrosis factor- $\alpha$ (TNF- $\alpha)$, TGF- $\beta$, EGF, damageassociated molecular pattern molecules, and some proteases are likely released by dying cells, as well as by the "broken" ECM and injured host tissue (Soulez et al., 2010; Peurichard et al., 2019). These factors activate mesenchymal stem cells, including adipose-derived stem cells (ASCs) and bone marrow mesenchymal stem cells (BMSCs), which recruit inflammatory cells (mainly neutrophils and macrophages) and endothelial progenitor cells, all of which play pivotal roles in the repair process (Suga et al., 2010; Yoshimura et al., 2011; Kato et al., 2014). For example, ASCs cooperate with pericytes and endothelial cells, both cells being partly derived from ASCs, to induce neovascularization in the grafts and form larger vessels that connect the grafts and recipient areas (Han et al., 2018). Then infiltrating neutrophils, granulocytes, and macrophages promote the clearance of free oil and the phagocytosis of dead cells following fat grafting, enhancing angiogenesis and adipogenesis (Phipps et al., 2015; Liu et al., 2018a). Moreover, these inflammatory reactions significantly stimulate the synthesis of several ECM proteins, including collagen, fibronectin, laminin, and elastins, by surviving cellular components, such as ASCs, preadipocytes, and adipocytes (Mariman and Wang, 2010; Lu 


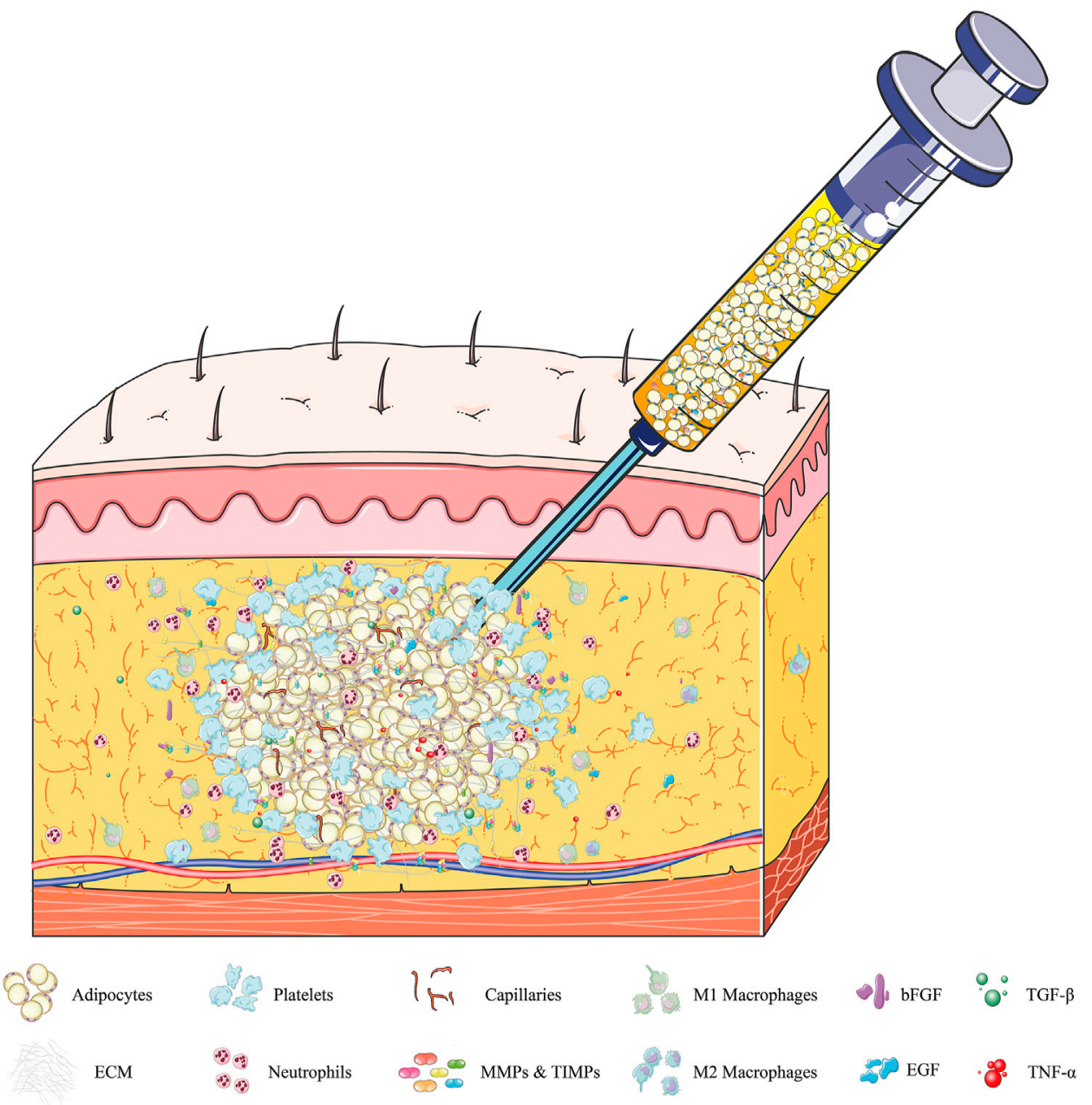

FIGURE 1 | Dynamic regulation of adipose ECM within $72 \mathrm{~h}$ after fat grafting. Local hemorrhage after injection of fat grafts at the recipient area activates platelet cascade reactions. The adipocytes are covered by platelets and form clots within a few hours. The thin layers of fibers (fragile collagen) secreted by platelets and myofibroblasts form a loose connection between adipose lobules and "broken" ECM within 24 h. During this period, dying adipocytes, SVF, and "broken" ECM secrete various cytokines, including bFGF, TNF- $\alpha$, TGF- $\beta$, and EGF; damage-related molecular pattern molecules; and some proteases, primarily MMPs and TIMPs. These factors recruit inflammatory cells (mainly neutrophils and macrophages), activate regenerative cells (such as stem cells and endothelial cells), and promote ECM synthesis, all of which play pivotal roles in the regeneration process. Abbreviations: SVF, stromal vascular fraction; bFGF, basic fibroblast growth factor; TNF- $\alpha$, tumor necrosis factor- $\alpha$; TGF- $\beta$, transforming growth factor- $\beta$; EGF, epidermal growth factor; MMPs, matrix metalloproteinases; TIMPs, tissue inhibitors of metalloproteinases.

et al., 2011; Zhang et al., 2020). Subsequently, most fat lobules are surrounded by a temporary network of collagen fibers, which are secreted by platelets and myofibroblasts within 3 days (Luo et al., 2016) (Figure 1). Until day 7, these fragile collagen fibers gradually thicken and form a complete ECM framework, with electron microscopy showing that almost all adipocytes were embedded in this newly formed cytoskeleton in the regenerating zone (Cai et al., 2017). However, a different process is observed in the core/necrotic zone, in which adipose tissues are loosely connected and collagen fibers are more fragile, thus preventing the establishment of a complete ECM framework (Kato et al., 2014; Khouri and Khouri, 2017) (Figure 2).

During the whole remodeling process of adipose ECM, the dynamic balance between matrix metalloproteinases (MMPs) and their inhibitors, tissue inhibitors of metalloproteinases
(TIMPs), plays a vital role in ECM degradation (Lin et al., 2016). MMPs are a family of calcium-dependent and zinccontaining endopeptidases that digest ECM proteins under both physiological and pathological conditions, resulting in the degradation and turnover of connective tissue and basement membrane proteins, such as collagens, proteoglycans, and elastin, as well as several circulating and cell surface components, thereby regulating cell behavior in numerous ways (Stamenkovic, 2003; Li et al., 2020). To date, 23 MMPs have been identified in human tissues; these proteins can be categorized as soluble-type (ST-MMPs) and membrane-bound type (MT-MMPs) (Sternlicht and Werb, 2001; Berg et al., 2019 Feb). Whereas ST-MMPs are secreted and diffuse directly into the ECM, MT-MMPs are bound to the plasma membrane and exert their enzymatic function(s) at the cell surface. The MMP most 


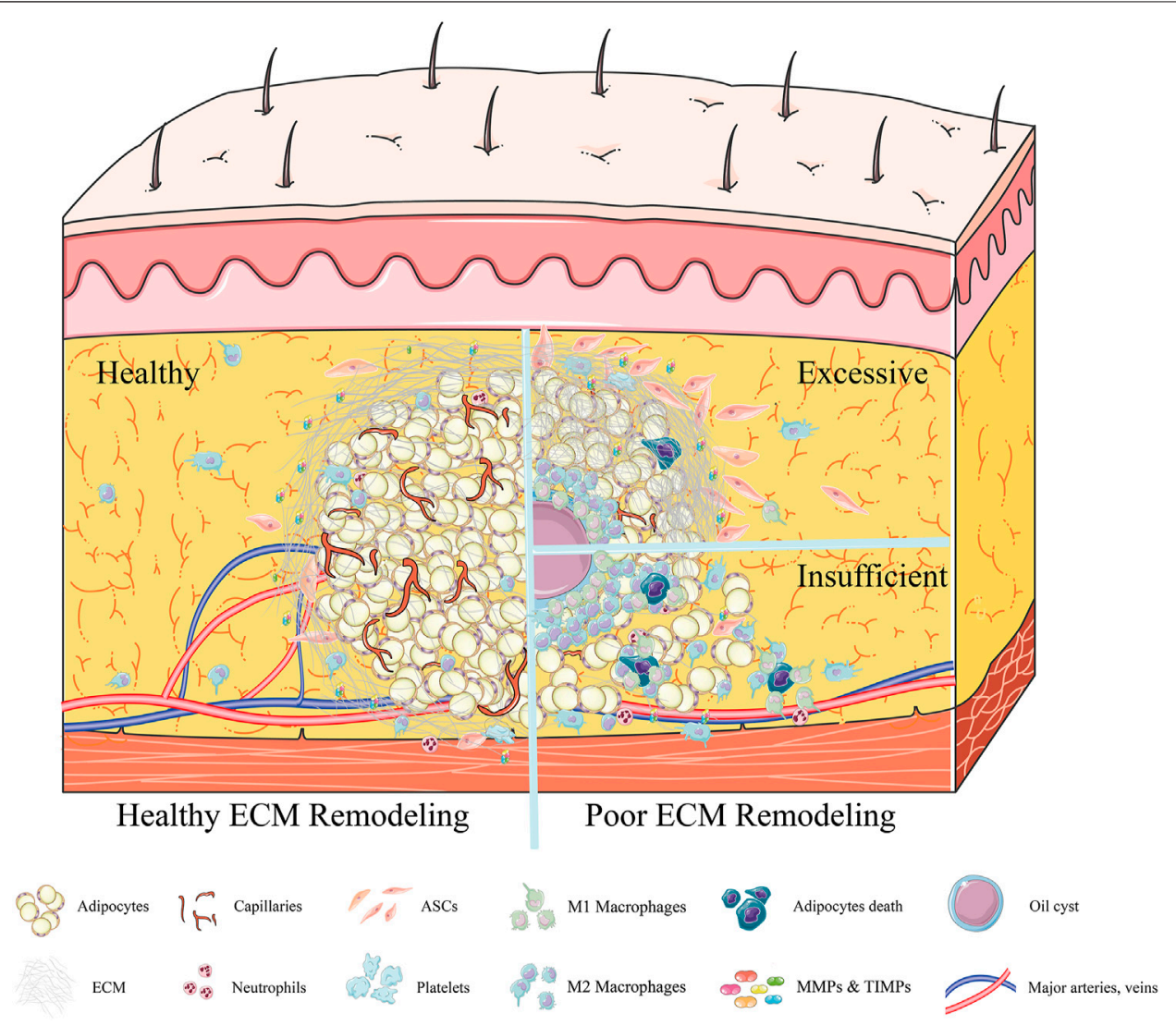

FIGURE 2 | Adipose ECM remodeling $\geq 7$ days after fat grafting. In an environment of healthy adipose ECM remodeling, the establishment of a new vascular network is accompanied by gradual thickening of the fragile collagen fibers, forming a complete ECM framework (left). Almost all adipocytes were embedded in this newly formed cytoskeleton, after which the inflammation subsides gradually. By contrast, in an environment of poor adipose ECM remodeling (right), excessive deposition of ECM is observed, increasing adipose tissue stiffness (right, above). Although high tissue stiffness can promote the migration of ASCs, it will inhibit the formation of new blood vessels. Due to poor neovascularization, oil cysts form and are surrounded by macrophages. Alternatively, the insufficient synthesis of ECM (right, below) can result in adipose lobules not being tightly embedded in the ECM framework. These floating fat cells will release oil droplets after necrosis, recruiting an excess number of macrophages and inducing chronic inflammation.

enriched in adipose tissue is MMP14, a key pericellular collagenase that can produce endotrophins (ETP) (Zhao et al., 2016; Li et al., 2020). ETP is a potent co-stimulator that triggers fibrosis, macrophage accumulation, and inflammation by digesting COL6a3, which accumulates in hypoxic adipose tissue (Park and Scherer, 2012). ETP can also digest collagens to prevent over-accumulation of the ECM in fat tissue and make room for new blood vessels, thus promoting the healthy regeneration of adipose tissue ( $\mathrm{Li}$ et al., 2020). Mice with a heterozygous deletion of the gene encoding MMP-14 cannot undergo regular ECM reconstruction, reducing their fat regeneration ability (Chun et al., 2010). After fat grafting, MMP14 plays a vital role in maintaining mechanical stresses, allowing healthy ECM digestion/remodification, including ameliorated inflammation and fibrosis, as well as improved glucose and lipid metabolism (Nacu et al., 2008; Chun et al., 2010). Other MMPs are also important for degrading collagen and participate in vasculature remodeling, angiogenesis, inflammation, and atherosclerotic plaque rupture (Catalán et al., 2012). MMP-12 is the major MMP that degrades elastin in mice, whereas both MMP-3 and MMP-10 degrade fibronectin; laminin; gelatins-I, III, IV, and V; collagen fibers; and proteoglycans (Filippov et al., 2003; Ruiz-Ojeda et al., 2019). MMP-2 and MMP-9 have been shown to be necessary for degradation of adipose ECM, with rapid degradation of these damaged ECM being the first step in the angiogenic process during remodeling (Miksztowicz et al., 2017; Berg et al., 2019 Feb). Moreover, MMP-2 and MMP-9 synthesis and release are increased during adipocyte differentiation in mice. Preadipocyte treatment with MMPs-2 and -9 inhibitors markedly decreased adipocyte differentiation, suggesting that MMPs- 2 and -9 could profoundly affect the behavior of cells residing on the ECM by altering ECM components (Bouloumié et al., 2001). MMP-7 and MMP-26 hydrolyze fibronectin/gelatins and digest human plasminogen, generating a fragment that inhibits angiogenesis, which may lead to poor adipogenesis after grafting (Maquoi et al., 2002; Hopps and Caimi, 2015).

MMPs are inhibited by specific endogenous TIMPs, a family of four protease inhibitors: TIMP-1, -2, -3, and -4 (Brew et al., 2000). TIMP-1 mostly inhibits ST-MMPs, whereas TIMP-2 can inhibit 
both ST- and MT-MMPs, with deletion of the gene encoding TIMP-2 inhibiting MMP14 (MT1-MMP)-dependent MMP2 activation (Chun et al., 2004; Kandalam et al., 2010). TIMP3 inhibits the DLK1 sheddase ADAM17 and MMP14, which has been implicated in ECM turnover, thereby modulating sDLK1 shedding and collagen I degradation (Fenech et al., 2015). TIMP3 expression is downregulated during adipogenesis and by inflammatory signals in adipocytes (Bernot et al., 2010). Although TIMPs may act as endogenous inhibitors of MMPs that are responsible for degrading excess ECM, it remains unclear whether the beneficial effects of increased TIMP activities are due solely to their suppression of MMP activities and their increase in ECM stability. Alternatively, beneficial effects of increased TIMP activities may be due to their targeting of other molecules, including ADAM (a disintegrin and metalloproteinase) and ADAMTS (ADAM with a thrombospondin type-1 motif) (Murphy, 2011).

The synthesis of ECM is the main process occurring in the recipient area during fat grafting. Relatively little is known, however, about the dominant cell type responsible for the synthesis of ECM. TGF- $\beta 1$ was found to activate fibroblasts, resulting in the expression of the myofibroblast marker $\alpha$-smooth muscle actin ( $\alpha$-SMA) and the production of ECM (Worthen et al., 2020). The fat regeneration process after grafting is partly similar to the tissue regeneration process during wound healing (Yoshimura et al., 2011; Kato et al., 2014; Horsley and Watt, 2017; Plikus et al., 2017). According to the classical view of skin wound healing, fibroblasts recruited from the dermis of intact skin adjacent to the site of inflammation promote wound healing and tissue repair by differentiating into myofibroblasts and depositing ECM (Shook et al., 2018). However, the expression of a-SMA during ECM production is not unique to a specific subset of fibroblasts. According to the fibrosis model of the liver, kidneys, and lungs, epithelial cells express a-SMA following dedifferentiation during the process of epithelial-mesenchymal transition, suggesting that epithelial cells may be the source of myofibroblasts (Iwano et al., 2002). Use of a pericyte fate mapping-technique showed that adult spinal cord scarforming cells are derived from pericyte progeny, indicating that pericytes are the cellular origin of fibrosis (Göritz et al., 2011). Myofibroblasts expressing a-SMA may therefore differentiate from a variety of cells, including fibroblasts, astrocytes (Villesen et al., 2020), pericytes (Humphreys et al., 2010), epithelial cells (Radisky et al., 2007), endothelial cells (Soucy and Romer, 2009), and stem cells (Desai et al., 2014).

The quantitative contribution of different cell types to ECM deposition in adipose tissue is difficult to determine. Treatment of human ASCs with TGF- $\beta 1$ increased their expression of $\alpha$-SMA and induced their differentiation into myofibroblasts, which increased ECM gene expression (Kakudo et al., 2012), with a subset of myofibroblasts that express CD26 reported to contribute to ECM deposition (Shook and Rodeheffer, 2017). Experiments in adipose tissue obtained from obese people have shown that contact between preadipocytes and inflammatory cells in adipose tissue may contribute to the synthesis of selective ECM molecules, suggesting that preadipocytes play a role in the formation of interstitial fibrosis (Keophiphath et al.,
2009). Stimulation of human preadipocytes with macrophage secretions was shown to enhance the synthesis of collagen, fibronectin, and fibrous depots (Divoux and Clement, 2011). Furthermore, cells in white adipose tissue (WAT) expressing PDGFRa, Gp38, CD29, and CD34 have strong regeneration ability, indicating that these cells have adipogenic potential and are involved in proliferation and fibrosis (Marcelin et al., 2017). Moreover, these cells can be subdivided according to their level of expression of CD9. CD9 ${ }^{\text {high }}$ cells express genes related to ECM deposition and have a greater fibrotic ability than CD ${ }^{\text {low }}$ cells (Marcelin et al., 2017). These findings indicate that the synthesis of ECM during adipose tissue regeneration is not dominated by a single cell type, but may be completed by the cooperation of multiple cell types. Among them, the myofibroblasts that express CD26 and the preadipocytes that express high levels of CD9 may be the main cell types responsible for ECM synthesis (Marcelin et al., 2017; Shook and Rodeheffer, 2017).

\section{FACTORS AFFECTING EXTRACELLULAR MATRIX REMODELING}

The process of ECM remodeling after grafting is regulated by their cellular contexts and microenvironments (Hyldig et al., 2017) (Figure 3).

\subsection{Hypoxia and Inflammation}

Hypoxic conditions are critical for ECM formation and remodeling in successful soft-tissue repair (Steinbrech et al., 1999). Adipose tissue has the highest $(50-60 \mathrm{mmHg}$ ) partial oxygen tension (pO2) among organs. After grafting, adipose tissue enters a state of severe ischemic hypoxia (such as $\mathrm{pO}_{2}<$ $15 \mathrm{mmHg}$ ) (Yoshimura et al., 2011). A recent study performed in HIF-1a knockout mice suggests that hypoxia is a powerful trigger of ECM remodeling, significantly affecting the ECM proteins synthesized by preadipocytes, as well as cell metabolism, including the secretion of high concentrations of elastase, cathepsin G, and/or MMPs (Pham, 2006; Keophiphath et al., 2009; Lu et al., 2011). Adequate hypoxia was shown to not only promote the proliferation and migration of ASCs (differentiable preadipocytes) and their secretion of growth factors (Chung et al., 2009; Chen et al., 2016; Riis et al., 2016), but to enhance the synthesis of ECM components, resulting in fibrosis (Sun et al., 2013). Hypoxia activates genes encoding collagen prolyl (P4HA1 and P4HA2) and lysyl (PLOD2) hydroxylases expression through hypoxia-inducible factor-1 (HIF-1) (Gilkes et al., 2013; Pang et al., 2020). P4HA1 and P4HA2 are necessary for collagen synthesis and regulate the proper $3 \mathrm{D}$ folding of newly synthesized procollagen chains (Aro et al., 2015). PLOD2 mediates remodeling of the ECM by adjusting its alignment, composition, and mechanical properties (RosellGarcía et al., 2019). Hypoxia was also found to up-regulate the expression of the $a-1$ chain of collagen types 1,3 , and 7 . The a-1 chain of collagen type 3 has been linked to the formation of type I collagen, the crucial component of the ECM (Dong et al., 2018). 


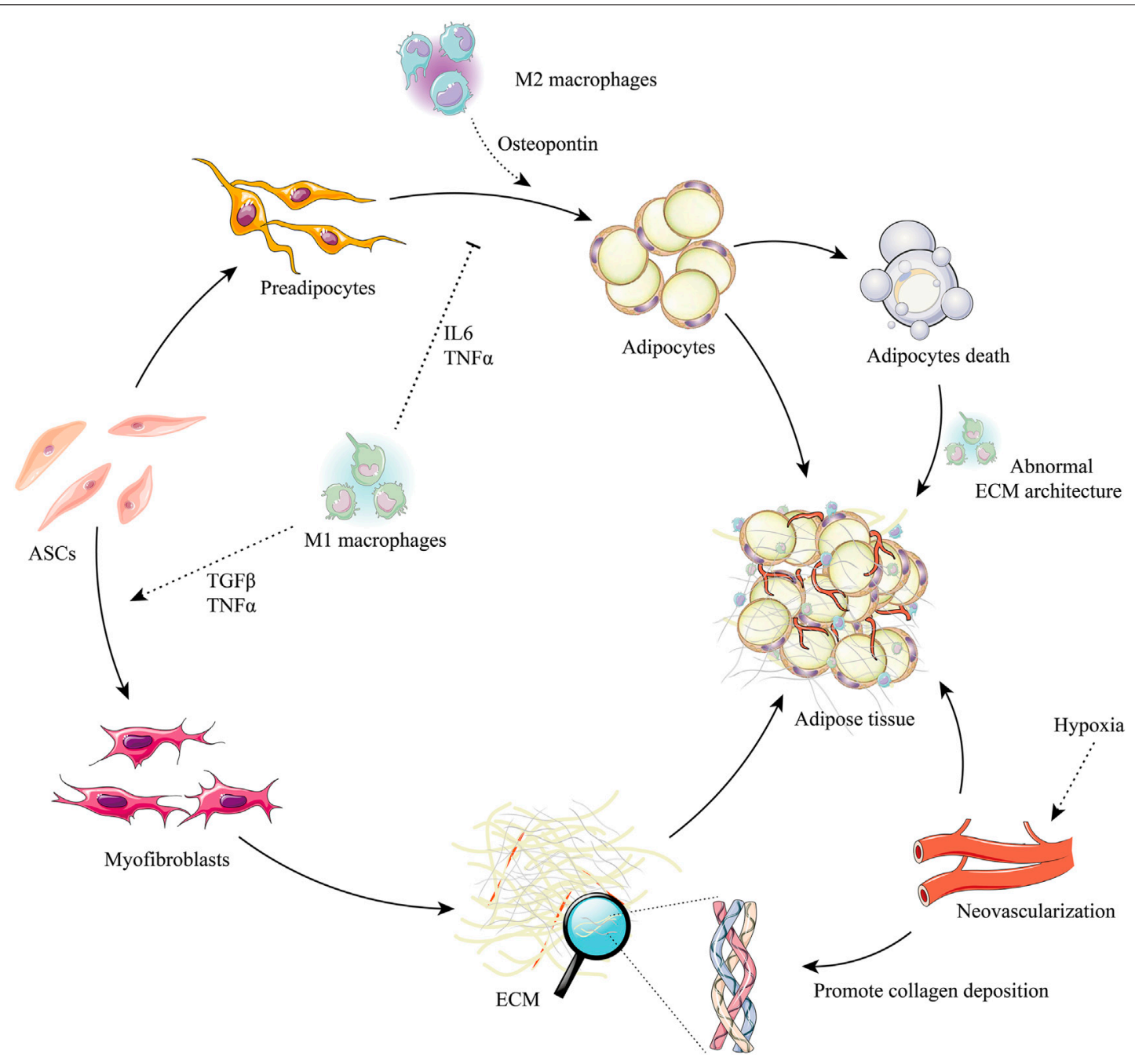

FIGURE 3 | ASCs, macrophages, and the regulation of adipose ECM remodeling after grafting. ASCs have the potential to differentiate into preadipocytes and myofibroblasts. M2 macrophage signals promote the adipogenesis of preadipocytes (e.g., osteopontin) and are suppressed by M1 macrophage signals (e.g., IL-6, TNFa). The ECM synthesis potential can trigger the myofibroblast phenotype in ASCs by M1 macrophages signals (e.g., TGF- $\beta$, TNF- $\alpha$ ). Adipocyte death will release profuse oil droplets, which activate M1 macrophages, promote abnormal ECM deposition, and induce the formation of myofibroblasts. Hypoxia stimulates neovascularization, which is beneficial to the synthesis of ECM and promotes healthy adipogenesis. Abbreviations: IL-6, interleukin-6; TGF- $\beta$, transforming growth factor-beta; TNF-a, tumor necrosis factor-alpha; M1 macrophages, classically activated macrophage; M2 macrophages, alternatively activated macrophage.

Severe hypoxia may play a fundamental role in the initiation of inflammation (Crewe et al., 2017). At present, neutrophils are believed to be one of the first types of cells recruited to trauma sites and are regarded as frontier inflammatory cells that initiate the regulation of inflammation downstream of fat grafting, and to play a key role in acute inflammation after fat transplantation (de Oliveira et al., 2016; Friedman et al., 2017; Liu et al., 2018a) (Figure 1). Neutrophils react quickly with and migrate to damaged tissue sites in response to molecular chemical inducers, including (C-X-C motif) ligand (CXCL) 1 to 3 , macrophage inflammatory protein-1 $\alpha, \mathrm{C} 5 \mathrm{a}$, and leukotriene B4 (Sadik et al., 2011; Lehman and Segal, 2020). At these sites, neutrophils phagocytize cell fragments and bacteria, forming neutrophil extracellular traps (Nets) and releasing reactive oxygen species (ROS), antimicrobial peptides, and serine proteases to remove necrotic and damaged tissue (Wilgus et al., 2013). Neutrophils also secrete large numbers of cytokines and pro-inflammatory factors, including interleukin (IL)-1 $\beta$, IL-6, IL-10, monocyte chemoattractant protein-1 (MCP$1)$, and CXCL1, which regulate inflammatory responses and induce immune cells (Trayhurn, 2014), mainly monocytes, to migrate to the anoxic zone, where they differentiate into proinflammatory macrophages (Pasarica et al., 2009; O'Rourke et al., 2011; Fujisaka et al., 2013). Neutrophils were shown to regulate angiogenesis by secreting MMP-9 (Deryugina et al., 2014). Moreover, high levels of neutrophils were found to be associated with enhanced angiogenesis (Dumitru et al., 2012; Tazzyman et al., 2013; Kim and Bae, 2016), which is crucial to adipose ECM remodeling (Lee et al., 2021). However, upregulation of neutrophils was recently found to lead to 
increased secretion of ROS and severe tissue damage, whereas downregulation of neutrophils reduced the expression of MMP-9 and inhibited angiogenesis (Souza et al., 2013; Chakraborty et al., 2020; Fetz et al., 2021). These findings suggested that the depletion and upregulation of neutrophils during early stages of fat transplantation impaired their long-term retention, indicating that undisturbed neutrophil function is the key to initiating downstream reactions that lead to the survival and evolution of transplanted fat grafts (Liu K. et al., 2018).

Three days after fat grafting, the numbers of neutrophils began to decrease and the numbers of macrophages began to increase, with macrophages becoming the main inflammatory cell component of fat grafts (Cai et al., 2017; Cai et al., 2018; Roh and Orgill, 2018). Macrophages play essential roles in fat regeneration after transplantation by, for example, removing apoptotic and necrotic cells, regulating angiogenesis, differentiating adipocyte precursors, and, especially, regulating collagen synthesis during early stages and remodeling the ECM during later stages (Schipper et al., 2012) (Figure 2). During the process of ECM remodeling, macrophages can significantly stimulate preadipocytes to synthesize several ECM proteins (Keophiphath et al., 2009); secrete high levels of elastase, cathepsin G, and MMPs; and degrade the ECM (Lu et al., 2011). Moreover, changes in polarization and cell density can allow macrophages to secrete large amounts of type VI collagen, leading to graft fat fibrosis (Schnoor et al., 2008).

During the first week after transplantation, grafts seem to enter an "inflammatory phase", similar to that after wound injury (Koh and DiPietro, 2011; Nissinen and Kähäri, 2015; Kim and Nair, 2019; Kloc et al., 2019). During this “inflammatory phase", most M1 macrophages become polarized and express high levels of TNF- $\alpha$, whereas pathogens and dead cells are cleared by neutrophils and macrophages (Cheng et al., 2019). M1 macrophages have phagocytic activity, produce proinflammatory mediators, and promote the fibrotic environment of local tissue (Werner and Grose, 2003; Wang et al., 2018). After grafting, M1 macrophages promote ECM remodeling by engulfing cellular debris, digesting damaged ECM components, and inducing the transformation of fibroblasts into ECM-secreting myofibroblasts by producing cytokines, including PDGF, TGF- $\beta$, and insulin-like growth factor (IGF)-1 in the grafts (Duffield et al., 2013). In addition, the M1 phenotype also can directly activate M1 factors, which drive a "feed-forward" state of inflammation and remodeling (IL$1 b$ ), and increase the production of MMPs and TIMPs, which drive ECM remodeling (Brown et al., 2012) (Figure 3).

Grafts are regarded as entering the "regeneration phase" 2-12 weeks after transplantation (Phipps et al., 2015). M2 macrophages gradually become the main macrophage group, producing high levels of TGF- $\beta$ and secreting a large number of angiogenic factors, such as vascular endothelial growth factor (VEGF), bFGF, and MMPs, a process involving RhoA/Rho kinase signaling and the induction of endothelial cell migration (Hoang et al., 2004) (Figure 3). This period is characterized by active adipogenesis and the gradual maturation of new microvascular networks (Seaman et al., 2016; Cai et al., 2018; Roh and Orgill, 2018). In addition, M2 macrophages can regulate or reverse the abnormal accumulation of ECM by secreting MMPs and other M2 factors, such as IL-10, RELMa, and Arg-1 (Brown et al., 2012). Mounting research suggests that the ECM remodeling of transferred fat is position-dependent and that M2 macrophages dominate in the deposition of ECM (Liao et al., 2011; Cai et al., 2017; Motz et al., 2021). The SEM results suggested that single dead adipocytes in the surviving zone are phagocytized by M1 macrophages, without excessive ECM deposition (fibrosis). By contrast, a mass of dead adipocytes in the regenerating and/or necrotizing zones are surrounded by an innermost single layer of M1 macrophages and outer multilayered M2 macrophages. This process is accompanied by the clearance of free oil and the phagocytosis of dead cells by M1 macrophages, along with excessive fibrosis by M2 macrophages (Kato et al., 2014).

Depletion of macrophages from fat grafts was shown to block angiogenesis and delay ECM remodeling by reducing MMP-2 expression (Debels et al., 2013; Cai et al., 2018). Moreover, low macrophage levels resulted in the downregulation of collagen synthesis and decreased collagen types I and VI expression, thereby inhibiting ECM deposition (Cai et al., 2017). By contrast, high macrophage levels at the early stage have been associated with increased angiogenesis and hematopoietic stem cell recruitment, enhancing ECM reconstruction and improving the survival rate of fat grafts (Roh and Orgill, 2018). In addition, upregulation of macrophage levels is time-dependent, and the excessive accumulation of early inflammatory cells may lead to extreme degradation of ECM (Cai et al., 2017). In comparison, the persistence of hyper-macrophages after the "regeneration phase" of transplanted fat seems to lead to excessive fibrosis, suggesting the need to control macrophage levels within a moderate range (Mineda et al., 2014).

\subsection{Angiogenesis}

Scanning electron microscopy (SEM) has shown that ECM remodeling is strongly linked to location and blood supply (Cai et al., 2017). After grafting, the fat lobules are closely embedded in the ECM framework around the capsule, where the survival area is located, with immunostaining showing high levels of type I collagen expression around the capsule. In the regenerated area, the adipose tissue seems to be less condensed, whereas in the necrotic area, the complete ECM framework has not yet been established, and the area positive for type I collagen is significantly reduced (Cai et al., 2017). These findings suggest that ECM remodeling after fat grafting is in agreement with the classical "three-zone" hypothesis, suggesting the importance of angiogenesis to ECM deposition (Eto et al., 2012). Stimulation of hypoxia promotes neovascularization through the angiogenesis induced by hypoxia-inducible factors- $1 \alpha$ (HIF-1 $\alpha$ ) and $2 \alpha$ (HIF2a) (Zhang et al., 2010; García-Martín et al., 2016) (Figure 3). An important determinant of their difference in activity is the abundance of specific PHD enzymes, which differ in specific proline hydroxylation sites on HIFa isoforms (Appelhoff et al., 2004). Moreover, they can interact with each other to induce angiogenesis. Interestingly, HIF-1 $\alpha$ alone is unable to induce an effective pro-angiogenic response in adipose tissue. Although HIF- $1 \alpha$ and HIF-2 $\alpha$ have overlapping effects on aspects of angiogenesis and ECM remodeling, increasing evidence 
indicates that HIF-1 $\alpha$ and HIF-2 $\alpha$ play unique roles in tissue regeneration (Skuli et al., 2009). HIF-1 $\alpha$ can increase expression of VEGF, PDGF, and nitric oxide synthase (NOS) (Feng et al., 2016), whereas HIF-2 $\alpha$ is thought to regulate the expression of Tie2 (the receptor tyrosine kinase for angiopoietin, Ang1, and Ang2), integrin, VEGF, VEGF receptor-1 (Flt-1), and VEGF receptor-2 (Flk-1), and can reduce inflammatory states (Skuli et al., 2009; Sun et al., 2013; Lee et al., 2014). Together with HIF$2 a$, HIF-1 $\alpha$ facilitates cellular adaptation to hypoxia and oxygen delivery by stimulating angiogenesis, erythropoiesis, and anaerobic glucose metabolism, thereby effectively promoting adipose tissue regeneration (Rankin et al., 2007).

Neovascularization during the regeneration stage after fat grafting depends on physical ECM guidance cues and is regulated by pro-angiogenic factors, such as VEGF, PDGFs, and bFGF (Siegel-Axel et al., 2014). Specifically, ASCs secrete MMPs (mainly MMP-2 and MMP-9) and cathepsins to further break down the ECM, liberate pericytes and endothelial cells from cell niches, and convert the characteristics of the basement membrane into a pro-angiogenic environment (van Dongen et al., 2019). In addition, the degradation of ECM also releases TGF- $\beta$ and various growth factors, such as VEGF and bFGF, from immobilized matrix stores (Plaks et al., 2015). As a vital regulator of physiological angiogenesis, VEGF promotes the growth of endothelial cells in vitro and causes angiogenesis in vivo. VEGF plays a key role in preventing endothelial cell apoptosis, regulating vascular permeability and inducing endothelial fenestration in some vascular beds (Lin et al., 2017). TGF- $\beta$ and PDGF are important regulators in the process of maintaining proper vascular function by coverage of mural cells and facilitating vessel maturation. They can up-regulate VEGF-A mRNA expression, and might act in concert to regulate angiogenesis and ECM production (Itoh et al., 2012). In addition, PDGF can stabilize endothelial cell channels by recruiting PDGF receptor- $\beta$ pericytes (Lin et al., 2017). Thus, the intimate homeostatic interactions among MMPs, proangiogenic factors, and other components of the ECM are critical in promoting the survival, migration, and proliferation of endothelial cells and their eventual differentiation into functional tubular networks (Van der Donckt et al., 2015).

In addition to increasing the rigidity of the vascular system, adipose ECM can directly promote or inhibit angiogenesis. Neovascularization and capillary morphogenesis after fat grafting partly depend on the balance between degradation and synthesis of the surrounding ECM (Lee et al., 2021). Formation of a stiffnessappropriate ( 2-4 kpa) network of collagen fibers within 7 days after fat grafting might promote the migration, proliferation, and differentiation of endothelial cells into functional tubular networks and the formation of functional blood vessels, which are essential for subsequent adipogenesis and tissue remodeling (Kniazeva and Putnam, 2009; Li et al., 2019). By contrast, excessive ECM deposition can affect the angiogenic properties of adipose tissue (Mongiat et al., 2016). For example, type IV collagen, a major vascular basement membrane protein, was found to inhibit initial neovascular sprouting during angiogenesis (Delaney et al., 2006). Another ECM component that plays a role in this process is type VI collagen, the main component of oil cyst walls that form after grafting. These ECM components are expected to stiffen tissue, making them less suitable for the proliferation of capillaries and the expansion of adipocytes (Kniazeva and Putnam, 2009; Kobayashi et al., 2020). Ultimately, a decrease of capillary density in new adipose tissue will negatively affect remodeling of the ECM, forming a vicious circle (Sun et al., 2013).

\subsection{Adipose-Derived Stem Cells}

ASCs are found within the stem cell niche and are surrounded by the ECM (Pope et al., 2016). In this specialized microenvironment, ECM proteins and various soluble factors regulate cell phenotype via the assembly of integrins, focal adhesions, and cytoskeletal reorganization to control the fates of ASCs (Rozario and DeSimone, 2010; Mecham, 2012; van Dongen et al., 2019) (Figure 3). ASCs, in turn, are closely associated with the composition, stiffness, and ligand pattern of the ECM (Flaim et al., 2008; Rozario and DeSimone, 2010; Choi et al., 2012; Harvestine et al., 2018).

The stiffness of adipose ECM plays a crucial role in cellular behavior, including the migration, proliferation, and differentiation of ASCs through mechanical transduction pathways. ECM deposition could increase adipose tissue stiffness, which promotes the migration of ASCs by upregulating the expression of cell migration-related proteins CDC42, RhoA, and dynamin (Zhang et al., 2020). However, excessive stiffness could affect the differentiation of ASCs, inhibiting their ability to differentiate into adipocytes and promoting the fibrosis of adipose tissue (Li et al., 2019).

The composition of ECM proteins secreted by ASCs undergoing remodeling during adipogenesis in vitro changes dynamically from fibronectin-rich to laminin-rich (Zhang et al., 2019). Similar results were observed in vivo, in that the cells moved from the growth phase to the differentiation phase, while the ECM transitions from a fibrillar to a laminar structure (Cai et al., 2016). Laminin has been shown to enhance adipogenesis (Hoshiba et al., 2010). Upregulation of laminin expression during the early stage has been found to initially increase the expression of type I collagen, but later to decrease its expression significantly (Mariman and Wang, 2010), followed by the alteration of ECM components from fibrillary collagen types I, III, and V to basement membrane types IV and VI(Mor-Yossef Moldovan et al., 2019). The components and proteins secreted by ASCs and preadipocytes optimized ECM remodeling and produced critical biochemical and physical signals (Morissette Martin et al., 2018). Exosomes derived from human adipose mesenchymal stem cells (hASCs-Exos) can be recruited to soft-tissue wound areas of a mouse skin incision model, increasing the production of collagen types I and III during early stages (Hu et al., 2016). During later stages, exosomes may reduce fibrosis by inhibiting the expression of collagen. ASCs have the potential to differentiate into fibroblasts (Hong et al., 2013; Ebnerasuly et al., 2017; Zhou et al., 2018), with VEGF promoting the differentiation of ASCs into fibroblasts and keratinocytes in vivo (Zhu et al., 2021). Moreover, the addition of fibroblast growth factor (FGF)-2 and ascorbic acid-2-phosphate can permanently induce the transition of ASCs into fibroblasts in vitro (Adams et al., 2012). When compared with primary fibroblasts, fibroblasts differentiated from ASCs were found to produce higher levels of healthy ECM markers, including elastin, fibronectin, and type I 
collagen (Gersch et al., 2020). ASC supplementation in an animal model of cell-assisted lipo-transfer was found to alter inflammatory processes, promote a favorable microenvironment for angiogenesis, contribute to a more rapid recovery from hypoxia and ischemia, and reduce the excessive deposition of collagen (Hong et al., 2018).

\section{TWO SITUATIONS OF POOR REMODELING OF ADIPOSE EXTRACELLULAR MATRIX AFTER GRAFTING: INSUFFICIENT AND EXCESSIVE}

Dysfunction of ECM remodeling during fat grafting may significantly affect graft retention rates. Insufficient synthesis of ECM will likely reduce graft retention rates, whereas excessive deposition of the ECM does not seem to be ideal for new fat regeneration (Cai et al., 2017). Remarkably loose, disorganized adipose tissue and an increase in adipocyte size have been observed in ColVI-/-ob/ob mice, suggesting that deficient synthesis of Col VI may lead to uncontrolled adipocyte expansion and a disordered structure after grafting (Divoux and Clement, 2011). Type I collagen played a positive role in the activation of YAP, promoting the differentiation of preadipocytes into myofibroblasts, which is regarded as a key culprit in fibrosis. These findings suggested that excessive Col I may inhibit adipogenesis via activation of YAP signaling (Liu X. et al., 2018; Xu et al., 2019; Liu et al., 2020). Rather, excessive ECM deposition will likely lead to fibrosis, eventually resulting in oil cyst formation and progressive calcification, outcomes much worse than a lack of retention (Juhl et al., 2018; Ørholt et al., 2020). These situations have been reported frequently and always occur in some parts of the "regenerating zone" and throughout the "necrotic zone" (Kato et al., 2014). Predictably, oil cysts and calcifications (central fat necrosis) occur when fat is grafted in large droplets $(>3 \mathrm{~mm})$ and when the microenvironment around the transplanted fat does not properly improve within the first $72 \mathrm{~h}$ (Suga et al., 2010; Yoshimura et al., 2011). Interestingly, single necrotic adipocytes are surrounded by fat cell-sized oil droplets and are phagocytized by a single layer of M1 macrophages, leaving almost no trace. By contrast, large areas of dead adipocytes surrounded by large oil droplets are, in turn, surrounded by multiple, stratified macrophages, consisting of an internal monolayer of M1 macrophages and an external multilayer of M2 macrophages, which form a crown-like structure (Eto et al., 2012). Locally persistent inflammation results in high levels of M2 macrophages surrounding oil cysts, inducing monocytes to produce angiogenic and fibrotic cytokines, including IL-4, IL-10, IL-13, and TGF- $\beta 1$ (Wick et al., 2013). Recent studies suggest that M2 macrophages may be key contributors to fibrogenesis and calcification (Braga et al., 2012; Bility et al., 2016; Hou et al., 2018). Thus, excessive ECM deposition, including fibrotic oil cysts and calcifications after fat grafting, may result from the overexpression of collagen types IV and VI, induced by upregulated M2 macrophages and fibrotic cytokines (Kim et al., 2015). The microenvironment of the walls of the oil cysts, such as the numbers of ASCs/progenitor cells and/or oxygen tension, may be insufficient for normal adipogenesis, resulting, even a few years later, in chronic inflammation in cyst walls (Mineda et al., 2014). Longterm follow-up of patients who have undergone autologous fat augmentation mammoplasty has shown that the oil cysts formed after grafting will remain problematic without surgical intervention (Tassinari et al., 2016; Juhl et al., 2018) (Figure 2).

\section{CLINICAL AVOIDANCE OF POOR EXTRACELLULAR MATRIX REMODELING AFTER GRAFTING}

Effective methods are necessary to improve the early-stage microenvironment of the graft, maintain the proper ECM remodeling, and avoid complications caused by incorrect techniques. Experimental results and previous experience suggest the feasibility of several methods (Table 1).

5.1 During the early stage after autologous fat grafting, circulating inflammatory cells, especially macrophages, will preferentially infiltrate the donor site. In this stage, the level of inflammation will be lower at the recipient than at the donor site, resulting in delayed repair of the recipient area, which may hinder the reconstruction of the ECM during the early stage (Wang et al., 2020). Thus, early supplementation of the recipient area with an adequate number of macrophages may increase the graft retention rate by improving angiogenesis and ECM remodeling (Phipps et al., 2015).

5.2 Chronic inflammation mediated by macrophages leads to dysfunction in ECM remodeling (Keophiphath et al., 2009; Kumar et al., 2018). Excessive macrophage infiltration can also result in the excess secretion of type VI collagen and result in fibrosis (Schnoor et al., 2008; Spencer et al., 2010). The rapid and massive infiltration and rapid evacuation of macrophages after fat grafting may lead to better tissue vascularization and facilitate ECM remodeling (Anghelina et al., 2006; Wang et al., 2020). Therefore, trying to deplete the macrophages from transferred fat during the late stage may reduce the excessive deposition of ECM and reduce fibrosis (Cai et al., 2017).

5.3 Ideal revascularization depends on the graft-to-recipient interface not exceeding a maximum of $1.6 \mathrm{~mm}$ (Khouri and Khouri, 2017). This interface may be optimized by a 3D distribution of the graft to reduce the obstacle of inadequate blood supply for remodeling of the ECM (Eto et al., 2012; Pu, 2012; Abu-Ghname et al., 2019). During fat injection, the cannula is first driven forward to create a tunnel in the recipient tissues, followed by fat injection during retraction, filling the tunnels with fat ribbons (Khouri et al., 2014b). Injection without cannula movement will lead to a fat blob, exceeding the optimal graftto-recipient interface distance (Khouri et al., 2014a). Therefore, injections should not be performed without cannula movement, and the injection speed should not exceed $0.1 \mathrm{ml} / 1 \mathrm{~cm}$ of cannula movement (Khouri and Khouri, 2017).

5.4 Autologous fat grafting supplemented with ASCs promotes vascular ingrowth at the recipient site and accelerates revascularization between donor and recipient tissues (Yoshimura et al., 2008; Yoshimura et al., 2010; Kølle et al., 2013; Hong et al., 2018; Yoshimura et al., 2020). ASC-assisted lipotransfer provides a better blood supply for remodeling of the ECM, but large, randomized, 
TABLE 1 | Clinical avoidance of poor ECM remodeling after grafting.

\section{Method}

Up-regulate the level of inflammation in the recipient area or supplement the transplanted recipient area with an adequate number of macrophages in the early stage Down-regulate the level of inflammation in the recipient area or deplete the macrophages in the transferred fat in the later stage

Injections should not be performed without cannula movement, and the injection speed should not exceed $0.1 \mathrm{ml} / 1 \mathrm{~cm}$ of cannula movement

Adipose-derived stem cells ASCs - assisted lipotransfer

The fat fraction in the lower liposuction high-quality fat is recommended as a suitable alternative for implantation Apply External volume expansion EVE on the recipient area pre-operation and post-operation
Principle

References

Macrophage mediated inflammation enhances the ECM protein synthesis in the early-stage

Depletion of macrophages relieved the fibrosis in the transferred fat during the late-stage

Ideal revascularization depends on the graft-to-recipient interface not exceeding a maximum of $1.6 \mathrm{~mm}$

ASCs - assisted lipotransfer can promote vascular ingrowth and accelerates revascularization between donor and recipient tissues

High-quality fat contains more ECM, ASCs, and higher anti-inflammatory and angiogenesis fat factors

EVE can enhance tissue vascularity, induce matrix deposition, increase adipose ECM's stiffness, regulate ASC proliferation and differentiation via shifting ECM synthesis from fibronectin to laminin
Wang et al. (2020); Phipps et al. (2015)

Keophiphath et al. (2009); Kumar et al. (2018); Schnoor et al. (2008); Spencer et al. (2010); Anghelina et al. (2006); Wang et al. (2020); Cai et al. (2017) Khouri and Khouri, (2017); Eto et al. (2012); Pu, (2012); Abu-Ghname et al. (2019); Khouri et al. (2014b); Khouri et al. (2014a)

Yoshimura et al. (2008); Yoshimura et al. (2010); Kolle et al. (2013); Hong et al. (2018); Yoshimura et al. (2020); Marks et al. (2017)

Allen et al. (2013); Qiu et al. (2016); De Francesco et al. (2017); Guan et al. (2020)

Heit et al. (2012); Lancerotto et al. (2013); Chin et al. (2016); Khouri et al. (2000); Zhang et al. (2020) controlled clinical trials have not yet been performed (Marks et al., 2017).

5.5 A graded density of fat can be obtained by centrifuging the products of liposuction using standard Coleman technology (Allen et al., 2013). Compared with the fat in the upper liposuction, the fat in the lower liposuction contains more ECM and ASCs, and higher concentrations of antiinflammatory and fat angiogenesis factors (Qiu et al., 2016; De Francesco et al., 2017). The fat fraction in the lower liposuction, which is called high-quality fat, is promising for improving vascularization and ECM remodeling, and is recommended as a suitable alternative for implantation (Guan et al., 2020).

5.6 External volume expansion (EVE) can enhance tissue vascularity, induce matrix deposition, and increase the stiffness of adipose ECM, which recruits circulating mesenchymal stromal cells (Heit et al., 2012; Lancerotto et al., 2013; Chin et al., 2016). In addition, EVE can regulate ASC proliferation and differentiation via shifting ECM synthesis from fibronectin to laminin, thereby priming the recipient site for autologous fat transfer (Khouri et al., 2000; Zhang et al., 2020).

5.7 Oil cysts filled with necrotic material result in persistent inflammation, and calcification continues to develop over time, with these progressive changes persisting (Mineda et al., 2014; Shida et al., 2017). Therefore, larger oil sacs should be suctioned under ultrasound guidance, taking care to ensure that all their contents are extracted (Shida et al., 2017). If the suction is incomplete, the lump will persist and the patient will be dissatisfied. Oil cysts that are not treated effectively during the early stages will develop into calcified masses surrounded by extensive calcified capsules (Tassinari et al., 2016). These lesions can only be treated by complete lumpectomy (Ørholt et al., 2020).

\section{CONCLUSION}

This review summarized the sources of ECM remodeling after fat grafting, as well as the mechanisms by which the ECM interacts with surrounding cells and microenvironments during the process of fat regeneration. These results provide a greater understanding of the application of fat repair and regeneration after grafting. ECM remodeling is regulated by extracellular molecular synthesis and degradation, accompanied by physiological reactions such as tissue development and repair, as well as by pathological processes such as hypoxia and inflammation (Clause and Barker, 2013). ECM remodeling also has a profound impact on the migration, proliferation, and differentiation of surrounding cells. Additional studies are needed to further assess the composition, function, and mechanism of regeneration of adipose tissue ECM (Mouw et al., 2014). These studies may reveal the directional control of the microenvironment and the cellular conditions beneficial to ECM remodeling, providing new concepts for improving the retention rate of adipose tissue after fat transplantation. Greater efforts are needed to apply these methods clinically.

\section{AUTHOR CONTRIBUTIONS}

All authors listed have made a substantial, direct and intellectual contribution to the work, and approved it for publication.

\section{FUNDING}

This work was supported by the National Nature Science Foundation of China (81871573, 81671931, 82072196, 82072197, 81772101, 81601702, 81801932). National Natural Science Foundation of Guangdong (2017A30313900, 2021A1515011623). Postdoctoral Science Foundation of China (2020M672723). Medical Scientific Research Foundation of Guangdong Province of China (A2020542). Administrator Foundation of Nanfang Hospital (2019B021). National undergraduate innovation and entrepreneurship training program (X202012121222, X202012121312). 


\section{REFERENCES}

Abu-Ghname, A., Perdanasari, A. T., and Reece, E. M. (2019). Principles and Applications of Fat Grafting in Plastic Surgery. Semin. Plast. Surg. 33, 147-154. doi:10.1055/s-0039-1693438

Adams, A. M., Arruda, E. M., and Larkin, L. M. (2012). Use of Adipose-Derived Stem Cells to Fabricate Scaffoldless Tissue-Engineered Neural Conduits In Vitro. Neuroscience 201, 349-356. doi:10.1016/j.neuroscience.2011.11.004

Aiba-Kojima, E., Tsuno, N. H., Inoue, K., Matsumoto, D., Shigeura, T., Sato, T., et al. (2007). Characterization of Wound Drainage Fluids as a Source of Soluble Factors Associated with Wound Healing: Comparison with Platelet-Rich Plasma and Potential Use in Cell Culture. Wound Repair Regen. 15, 511-520. doi:10.1111/j.1524-475X.2007.00259.x

Aikio, M., Elamaa, H., Vicente, D., Izzi, V., Kaur, I., Seppinen, L., et al. (2014). Specific Collagen XVIII Isoforms Promote Adipose Tissue Accrual via Mechanisms Determining Adipocyte Number and Affect Fat Deposition. Proc. Natl. Acad. Sci. 111, E3043-E3052. doi:10.1073/pnas.1405879111

Alkhouli, N., Mansfield, J., Green, E., Bell, J., Knight, B., Liversedge, N., et al. (2013). The Mechanical Properties of Human Adipose Tissues and Their Relationships to the Structure and Composition of the Extracellular Matrix. Am. J. PhysiologyEndocrinology Metab. 305, E1427-E1435. doi:10.1152/ajpendo.00111.2013

Allen, R. J., Canizares, O., Scharf, C., Nguyen, P. D., Thanik, V., Saadeh, P. B., et al. (2013). Grading Lipoaspirate. Plast. Reconstr. Surg. 131, 38-45. doi:10.1097/ PRS.0b013e3182729cc6

Anghelina, M., Krishnan, P., Moldovan, L., and Moldovan, N. I. (2006). Monocytes/Macrophages Cooperate with Progenitor Cells during Neovascularization and Tissue Repair. Am. J. Pathol. 168, 529-541. doi:10.2353/ajpath.2006.050255

Appelhoff, R. J., Tian, Y.-M., Raval, R. R., Turley, H., Harris, A. L., Pugh, C. W., et al. (2004). Differential Function of the Prolyl Hydroxylases PHD1, PHD2, and PHD3 in the Regulation of Hypoxia-Inducible Factor. J. Biol. Chem. 279, 38458-38465. doi:10.1074/jbc.M406026200

Aro, E., Salo, A. M., Khatri, R., Finnilä, M., Miinalainen, I., Sormunen, R., et al. (2015). Severe Extracellular Matrix Abnormalities and Chondrodysplasia in Mice Lacking Collagen Prolyl 4-Hydroxylase Isoenzyme II in Combination with a Reduced Amount of Isoenzyme I. J. Biol. Chem. 290, 16964-16978. doi:10.1074/jbc.M115.662635

Berg, G., Barchuk, M., and Miksztowicz, V. (2019). Behavior of Metalloproteinases in Adipose Tissue, Liver and Arterial Wall: An Update of Extracellular Matrix Remodeling. Cells 8, 158. doi:10.3390/cells8020158

Bernot, D., Barruet, E., Poggi, M., Bonardo, B., Alessi, M.-C., and Peiretti, F. (2010). Down-regulation of Tissue Inhibitor of Metalloproteinase-3 (TIMP-3) Expression Is Necessary for Adipocyte Differentiation. J. Biol. Chem. 285, 6508-6514. doi:10.1074/jbc.M109.078444

Bility, M. T., Nio, K., Li, F., Mcgivern, D. R., Lemon, S. M., Feeney, E. R., et al. (2016). Chronic Hepatitis C Infection-Induced Liver Fibrogenesis Is Associated with M2 Macrophage Activation. Sci. Rep. 6, 39520. doi:10.1038/srep39520

Bouloumie, A., Sengenes, C., Portolan, G., Galitzky, J., and Lafontan, M. (2001). Adipocyte Produces Matrix Metalloproteinases 2 and 9: Involvement in Adipose Differentiation. Diabetes 50, 2080-2086. doi:10.2337/ diabetes.50.9.2080

Braga, T. T., Correa-Costa, M., Guise, Y. F. S., Castoldi, A., De Oliveira, C. D., Hyane, M. I., et al. (2012). MyD88 Signaling Pathway Is Involved in Renal Fibrosis by Favoring a TH2 Immune Response and Activating Alternative M2 Macrophages. Mol. Med. 18, 1231-1239. doi:10.2119/molmed.2012.00131

Brew, K., Dinakarpandian, D., and Nagase, H. (2000). Tissue Inhibitors of Metalloproteinases: Evolution, Structure and Function. Biochim. Biophys. Acta (Bba) - Protein Struct. Mol. Enzymol. 1477, 267-283. doi:10.1016/ s0167-4838(99)00279-4

Brown, B. N., Freund, J. M., Han, L., Rubin, J. P., Reing, J. E., Jeffries, E. M., et al. (2011). Comparison of Three Methods for the Derivation of a Biologic Scaffold Composed of Adipose Tissue Extracellular Matrix. Tissue Eng. C: Methods 17, 411-421. doi:10.1089/ten.TEC.2010.0342

Brown, B. N., Ratner, B. D., Goodman, S. B., Amar, S., and Badylak, S. F. (2012). Macrophage Polarization: an Opportunity for Improved Outcomes in Biomaterials and Regenerative Medicine. Biomaterials 33, 3792-3802. doi:10.1016/j.biomaterials.2012.02.034
Cai, J., Feng, J., Liu, K., Zhou, S., and Lu, F. (2018). Early Macrophage Infiltration Improves Fat Graft Survival by Inducing Angiogenesis and Hematopoietic Stem Cell Recruitment. Plast. Reconstr. Surg. 141, 376-386. doi:10.1097/ PRS.0000000000004028

Cai, J., Li, B., Liu, K., Li, G., and Lu, F. (2017). Macrophage Infiltration Regulates the Adipose ECM Reconstruction and the Fibrosis Process after Fat Grafting. Biochem. Biophysical Res. Commun. 490, 560-566. doi:10.1016/ j.bbrc.2017.06.078

Cai, R., Nakamoto, T., Hoshiba, T., Kawazoe, N., and Chen, G. (2016). Matrices Secreted during Simultaneous Osteogenesis and Adipogenesis of Mesenchymal Stem Cells Affect Stem Cells Differentiation. Acta Biomater. 35, 185-193. doi:10.1016/j.actbio.2016.02.009

Catalán, V., Gómez-Ambrosi, J., Rodríguez, A., and Frühbeck, G. (2012). Role of Extracellular Matrix Remodelling in Adipose Tissue Pathophysiology: Relevance in the Development of Obesity. Histol. Histopathol 27, 1515-1528. doi:10.14670/HH-27.1515

Chakraborty, P., Dalpati, N., Bhan, C., Dash, S. P., Kumar, P., and Sarangi, P. P. (2020). A C-Terminal Fragment of Adhesion Protein Fibulin7 Regulates Neutrophil Migration and Functions and Improves Survival in LPS Induced Systemic Inflammation. Cytokine 131, 155113. doi:10.1016/j.cyto.2020.155113

Chen, X., Yan, L., Guo, Z., Chen, Z., Chen, Y., Li, M., et al. (2016). Adipose-derived Mesenchymal Stem Cells Promote the Survival of Fat Grafts via Crosstalk between the Nrf2 and TLR4 Pathways. Cell Death Dis 7, e2369. doi:10.1038/ cddis. 2016.261

Cheng, H., Luan, J., Mu, D., Wang, Q., Qi, J., Li, Z., et al. (2019). M1/M2 Macrophages Play Different Roles in Adipogenic Differentiation of PDGFRa+ Preadipocytes In Vitro. Aesth Plast. Surg. 43, 514-520. doi:10.1007/s00266-018-1294-8

Cheriyan, T., Kao, H. K., Qiao, X., and Guo, L. (2014). Low Harvest Pressure Enhances Autologous Fat Graft Viability. Plast. Reconstr. Surg. 133, 1365-1368. doi:10.1097/prs.0000000000000185

Chin, M. S., Lujan-Hernandez, J., Babchenko, O., Bannon, E., Perry, D. J., Chappell, A. G., et al. (2016). External Volume Expansion in Irradiated Tissue. Plast. Reconstr. Surg. 137, 799e-807e. doi:10.1097/PRS.0000000000002081

Choi, Y. S., Vincent, L. G., Lee, A. R., Kretchmer, K. C., Chirasatitsin, S., Dobke, M. K., et al. (2012). The Alignment and Fusion Assembly of Adipose-Derived Stem Cells on Mechanically Patterned Matrices. Biomaterials 33, 6943-6951. doi:10.1016/j.biomaterials.2012.06.057

Chun, T.-H., Inoue, M., Morisaki, H., Yamanaka, I., Miyamoto, Y., Okamura, T., et al. (2010). Genetic Link between Obesity andMMP14-dependent Adipogenic Collagen Turnover. Diabetes 59, 2484-2494. doi:10.2337/db10-0073

Chun, T.-H., Sabeh, F., Ota, I., Murphy, H., Mcdonagh, K. T., Holmbeck, K., et al. (2004). MT1-MMP-dependent Neovessel Formation within the Confines of the Three-Dimensional Extracellular Matrix. J. Cel Biol 167, 757-767. doi:10.1083/ jcb.200405001

Chung, H.-M., Won, C.-H., and Sung, J.-H. (2009). Responses of Adipose-Derived Stem Cells during Hypoxia: Enhanced Skin-Regenerative Potential. Expert Opin. Biol. Ther. 9, 1499-1508. doi:10.1517/14712590903307362

Clause, K. C., and Barker, T. H. (2013). Extracellular Matrix Signaling in Morphogenesis and Repair. Curr. Opin. Biotechnol. 24, 830-833. doi:10.1016/j.copbio.2013.04.011

Crewe, C., An, Y. A., and Scherer, P. E. (2017). The Ominous Triad of Adipose Tissue Dysfunction: Inflammation, Fibrosis, and Impaired Angiogenesis. J. Clin. Invest. 127, 74-82. doi:10.1172/JCI88883

De Francesco, F., Guastafierro, A., Nicoletti, G., Razzano, S., Riccio, M., and Ferraro, G. (2017). The Selective Centrifugation Ensures a Better In Vitro Isolation of ASCs and Restores a Soft Tissue Regeneration In Vivo. Ijms 18, 1038. doi:10.3390/ijms18051038

De Oliveira, S., Rosowski, E. E., and Huttenlocher, A. (2016). Neutrophil Migration in Infection and Wound Repair: Going Forward in Reverse. Nat. Rev. Immunol. 16, 378-391. doi:10.1038/nri.2016.49

Debels, H., Galea, L., Han, X.-L., Palmer, J., Van Rooijen, N., Morrison, W., et al. (2013). Macrophages Play a Key Role in Angiogenesis and Adipogenesis in a Mouse Tissue Engineering Model. Tissue Eng. A 19, 2615-2625. doi:10.1089/ ten.TEA.2013.0071

Delaney, C. E., Weagant, B. T., and Addison, C. L. (2006). The Inhibitory Effects of Endostatin on Endothelial Cells Are Modulated by Extracellular Matrix. Exp. Cel Res. 312, 2476-2489. doi:10.1016/j.yexcr.2006.04.003 
Deryugina, E. I., Zajac, E., Juncker-Jensen, A., Kupriyanova, T. A., Welter, L., and Quigley, J. P. (2014). Tissue-infiltrating Neutrophils Constitute the Major In Vivo Source of Angiogenesis-Inducing MMP-9 in the Tumor Microenvironment. Neoplasia 16, 771-788. doi:10.1016/j.neo.2014.08.013

Desai, V. D., Hsia, H. C., and Schwarzbauer, J. E. (2014). Reversible Modulation of Myofibroblast Differentiation in Adipose-Derived Mesenchymal Stem Cells. PLoS One 9, e86865. doi:10.1371/journal.pone.0086865

Divoux, A., and Clément, K. (2011). Architecture and the Extracellular Matrix: the Still Unappreciated Components of the Adipose Tissue. Obes. Rev. 12, e494-e503. doi:10.1111/j.1467-789X.2010.00811.x

Dong, J., Yu, M., Zhang, Y., Yin, Y., and Tian, W. (2018). Recent Developments and Clinical Potential on Decellularized Adipose Tissue. J. Biomed. Mater. Res. 106, 2563-2574. doi:10.1002/jbm.a.36435

Dongen, J. A., Getova, V., Brouwer, L. A., Liguori, G. R., Sharma, P. K., Stevens, H. P., et al. (2019). Adipose Tissue-derived Extracellular Matrix Hydrogels as a Release Platform for Secreted Paracrine Factors. J. Tissue Eng. Regen. Med. 13, 973-985. doi:10.1002/term.2843

Duffield, J. S., Lupher, M., Thannickal, V. J., and Wynn, T. A. (2013). Host Responses in Tissue Repair and Fibrosis. Annu. Rev. Pathol. Mech. Dis. 8, 241-276. doi:10.1146/annurev-pathol-020712-163930

Dumitru, C. A., Moses, K., Trellakis, S., Lang, S., and Brandau, S. (2012). Neutrophils and Granulocytic Myeloid-Derived Suppressor Cells: Immunophenotyping, Cell Biology and Clinical Relevance in Human Oncology. Cancer Immunol. Immunother. 61, 1155-1167. doi:10.1007/s00262-012-1294-5

Ebnerasuly, F., Hajebrahimi, Z., Tabaie, S. M., and Darbouy, M. (2017). Effect of Simulated Microgravity Conditions on Differentiation of Adipose Derived Stem Cells towards Fibroblasts Using Connective Tissue Growth Factor. Iran. J. Biotechnol. 15, 241-251. doi:10.15171/ijb.1747

Eto, H., Kato, H., Suga, H., Aoi, N., Doi, K., Kuno, S., et al. (2012). The Fate of Adipocytes after Nonvascularized Fat Grafting. Plast. Reconstr. Surg. 129, 1081-1092. doi:10.1097/PRS.0b013e31824a2b19

Fenech, M., Gavrilovic, J., and Turner, J. (2015). Effect of Tissue Inhibitor of Metalloproteinases 3 on DLK1 Shedding in Cultured Human Pre-adipocytes and Implications for Adipose Tissue Remodelling. Lancet 385 (Suppl. 1), S35. doi:10.1016/S0140-6736(15)60350-6

Feng, N., Chen, H., Fu, S., Bian, Z., Lin, X., Yang, L., et al. (2016). HIF-1a and HIF$2 \alpha$ Induced Angiogenesis in Gastrointestinal Vascular Malformation and Reversed by Thalidomide. Sci. Rep. 6, 27280. doi:10.1038/srep27280

Fetz, A. E., Radic, M. Z., and Bowlin, G. L. (2021). Neutrophils in BiomaterialGuided Tissue Regeneration: Matrix Reprogramming for Angiogenesis. Tissue Eng. B: Rev. 27, 95-106. doi:10.1089/ten.TEB.2020.0028

Filippov, S., Caras, I., Murray, R., Matrisian, L. M., Chapman, H. A., Shapiro, S., et al. (2003). Matrilysin-dependent Elastolysis by Human Macrophages. J. Exp. Med. 198, 925-935. doi:10.1084/jem.20030626

Flaim, C. J., Teng, D., Chien, S., and Bhatia, S. N. (2008). Combinatorial Signaling Microenvironments for Studying Stem Cell Fate. Stem Cell Dev. 17, 29-40. doi:10.1089/scd.2007.0085

Friedman, O., Carmel, N., Sela, M., Abu Jabal, A., Inbal, A., Ben Hamou, M., et al. (2017). Immunological and Inflammatory Mapping of Vascularized Composite Allograft Rejection Processes in a Rat Model. PLoS One 12, e0181507. doi:10.1371/journal.pone.0181507

Fujisaka, S., Usui, I., Ikutani, M., Aminuddin, A., Takikawa, A., Tsuneyama, K., et al. (2013). Adipose Tissue Hypoxia Induces Inflammatory M1 Polarity of Macrophages in an HIF-1 $\alpha$-dependent and HIF-1 $\alpha$-independent Manner in Obese Mice. Diabetologia 56, 1403-1412. doi:10.1007/s00125-013-2885-1

García-Martín, R., Alexaki, V. I., Qin, N., Rubín de Celis, M. F., Economopoulou, M., Ziogas, A., et al. (2016). Adipocyte-Specific Hypoxia-Inducible Factor $2 a$ Deficiency Exacerbates Obesity-Induced Brown Adipose Tissue Dysfunction and Metabolic Dysregulation. Mol. Cel Biol 36, 376-393. doi:10.1128/ MCB.00430-15

Geeroms, M., Hamdi, M., Hirano, R., Hagiwara, H., Fujimura, S., Mizuno, H., et al. (2019). Quality and Quantity-Cultured Murine Endothelial Progenitor Cells Increase Vascularization and Decrease Fibrosis in the Fat Graft. Plast. Reconstr. Surg. 143, 744e-755e. doi:10.1097/PRS.0000000000005439

Gersch, R. P., Raum, J. C., Calvert, C., and Percec, I. (2020). Fibroblasts Derived from Human Adipose Stem Cells Produce More Effective Extracellular Matrix and Migrate Faster Compared to Primary Dermal Fibroblasts. Aesthet. Surg. J. 40, 108-117. doi:10.1093/asj/sjz071
Gilkes, D. M., Bajpai, S., Chaturvedi, P., Wirtz, D., and Semenza, G. L. (2013). Hypoxia-inducible Factor 1 (HIF-1) Promotes Extracellular Matrix Remodeling under Hypoxic Conditions by Inducing P4HA1, P4HA2, and PLOD2 Expression in Fibroblasts. J. Biol. Chem. 288, 10819-10829. doi:10.1074/jbc.M112.442939

Göritz, C., Dias, D. O., Tomilin, N., Barbacid, M., Shupliakov, O., and Frisén, J. (2011). A Pericyte Origin of Spinal Cord Scar Tissue. Science 333, 238-242. doi:10.1126/science. 1203165

Guan, J., He, Y., Wang, X., Yao, Y., Li, Y., Wang, Z., et al. (2020). Identification of High-Quality Fat Based on Precision Centrifugation in Lipoaspirates Using Marker Floats. Plast. Reconstr. Surg. 146, 541-550. doi:10.1097/ PRS. 0000000000007063

Han, Y.-d., Bai, Y., Yan, X.-l., Ren, J., Zeng, Q., Li, X.-d., et al. (2018). Cotransplantation of Exosomes Derived from Hypoxia-Preconditioned Adipose Mesenchymal Stem Cells Promotes Neovascularization and Graft Survival in Fat Grafting. Biochem. Biophysical Res. Commun. 497, 305-312. doi:10.1016/ j.bbrc.2018.02.076

Harvestine, J. N., Orbay, H., Chen, J. Y., Sahar, D. E., and Leach, J. K. (2018). Cellsecreted Extracellular Matrix, Independent of Cell Source, Promotes the Osteogenic Differentiation of Human Stromal Vascular Fraction. J. Mater. Chem. B 6, 4104-4115. doi:10.1039/C7TB02787G

Heit, Y. I., Lancerotto, L., Mesteri, I., Ackermann, M., Navarrete, M. F., Nguyen, C. T., et al. (2012). External Volume Expansion Increases Subcutaneous Thickness, Cell Proliferation, and Vascular Remodeling in a Murine Model. Plast. Reconstr. Surg. 130, 541-547. doi:10.1097/PRS.0b013e31825dc04d

Hoang, M. V., Whelan, M. C., and Senger, D. R. (2004). Rho Activity Critically and Selectively Regulates Endothelial Cell Organization during Angiogenesis. Pnas 101, 1874-1879. doi:10.1073/pnas.0308525100

Hong, K. Y., Yim, S., Kim, H. J., Jin, U. S., Lim, S., Eo, S., et al. (2018). The Fate of the Adipose-Derived Stromal Cells during Angiogenesis and Adipogenesis after Cell-Assisted Lipotransfer. Plast. Reconstr. Surg. 141, 365-375. doi:10.1097/ PRS.0000000000004021

Hong, S. J., Jia, S.-X., Xie, P., Xu, W., Leung, K. P., Mustoe, T. A., et al. (2013). Topically Delivered Adipose Derived Stem Cells Show an Activated-Fibroblast Phenotype and Enhance Granulation Tissue Formation in Skin Wounds. PLoS One 8, e55640. doi:10.1371/journal.pone.0055640

Hopps, E., and Caimi, G. (2015). Matrix Metalloproteases as a Pharmacological Target in Cardiovascular Diseases. Eur. Rev. Med. Pharmacol. Sci. 19, 2583-2589.

Horsley, V., and Watt, F. (2017). Repeal and Replace: Adipocyte Regeneration in Wound Repair. Cell Stem Cell 20, 424-426. doi:10.1016/j.stem.2017.03.015

Hoshiba, T., Kawazoe, N., Tateishi, T., and Chen, G. (2010). Development of Extracellular Matrices Mimicking Stepwise Adipogenesis of Mesenchymal Stem Cells. Adv. Mater. 22, 3042-3047. doi:10.1002/adma.201000038

Hou, J., Shi, J., Chen, L., Lv, Z., Chen, X., Cao, H., et al. (2018). M2 Macrophages Promote Myofibroblast Differentiation of LR-MSCs and Are Associated with Pulmonary Fibrogenesis. Cell Commun Signal 16, 89. doi:10.1186/s12964-018-0300-8

Hu, L., Wang, J., Zhou, X., Xiong, Z., Zhao, J., Yu, R., et al. (2016). Exosomes Derived from Human Adipose Mensenchymal Stem Cells Accelerates Cutaneous Wound Healing via Optimizing the Characteristics of Fibroblasts. Sci. Rep. 6, 32993. doi:10.1038/srep32993

Humphreys, B. D., Lin, S.-L., Kobayashi, A., Hudson, T. E., Nowlin, B. T., Bonventre, J. V., et al. (2010). Fate Tracing Reveals the Pericyte and Not Epithelial Origin of Myofibroblasts in Kidney Fibrosis. Am. J. Pathol. 176, 85-97. doi:10.2353/ajpath.2010.090517

Hyldig, K., Riis, S., Pennisi, C., Zachar, V., and Fink, T. (2017). Implications of Extracellular Matrix Production by Adipose Tissue-Derived Stem Cells for Development of Wound Healing Therapies. Ijms 18, 1167. doi:10.3390/ ijms 18061167

Itoh, F., Itoh, S., Adachi, T., Ichikawa, K., Matsumura, Y., Takagi, T., et al. (2012). Smad2/Smad3 in Endothelium Is Indispensable for Vascular Stability via S1PR1 and N-Cadherin Expressions. Blood 119, 5320-5328. doi:10.1182/blood-201112-395772

Iwano, M., Plieth, D., Danoff, T. M., Xue, C., Okada, H., and Neilson, E. G. (2002). Evidence that Fibroblasts Derive from Epithelium during Tissue Fibrosis. J. Clin. Invest. 110, 341-350. doi:10.1172/JCI1551810.1172/jci0215518

Juhl, A. A., Redsted, S., and Engberg Damsgaard, T. (2018). Autologous Fat Grafting after Breast Conserving Surgery: Breast Imaging Changes and 
Patient-Reported Outcome. J. Plast. Reconstr. Aesthet. Surg. 71, 1570-1576. doi:10.1016/j.bjps.2018.08.012

Kakudo, N., Kushida, S., Suzuki, K., Ogura, T., Notodihardjo, P. V., Hara, T., et al. (2012). Effects of Transforming Growth Factor-Betal on Cell Motility, Collagen Gel Contraction, Myofibroblastic Differentiation, and Extracellular Matrix Expression of Human Adipose-Derived Stem Cell. Hum. Cel 25, 87-95. doi:10.1007/s13577-012-0049-0

Kandalam, V., Basu, R., Abraham, T., Wang, X., Soloway, P. D., Jaworski, D. M., et al. (2010). TIMP2 Deficiency Accelerates Adverse post-myocardial Infarction Remodeling Because of Enhanced MT1-MMP Activity Despite Lack of MMP2 Activation. Circ. Res. 106, 796-808. doi:10.1161/CIRCRESAHA.109.209189

Kato, H., Mineda, K., Eto, H., Doi, K., Kuno, S., Kinoshita, K., et al. (2014). Degeneration, Regeneration, and Cicatrization after Fat Grafting. Plast. Reconstr. Surg. 133, 303e-313e. doi:10.1097/PRS.0000000000000066

Keophiphath, M., Achard, V., Henegar, C., Rouault, C., Cle'ment, K., and Lacasa, D. (2009). Macrophage-secreted Factors Promote a Profibrotic Phenotype in Human Preadipocytes. Mol. Endocrinol. 23, 11-24. doi:10.1210/me.2008-0183

Khouri, R. K., and Khouri, R. K. (2017). Current Clinical Applications of Fat Grafting. Plast. Reconstr. Surg. 140, 466e-486e. doi:10.1097/ PRS.0000000000003648

Khouri, R. K., Rigotti, G., Cardoso, E., Khouri, R. K., and Biggs, T. M. (2014a). Megavolume Autologous Fat Transfer. Plast. Reconstr. Surg. 133, 550-557. doi:10.1097/01.prs.0000438044.06387.2a

Khouri, R. K., Rigotti, G., Cardoso, E., Khouri, R. K., and Biggs, T. M. (2014b). Megavolume Autologous Fat Transfer. Plast. Reconstr. Surg. 133, 1369-1377. doi:10.1097/PRS.0000000000000179

Khouri, R. K., Schlenz, I., Murphy, B. J., and Baker, T. J. (2000). Nonsurgical Breast Enlargement Using an External Soft-Tissue Expansion System. Plast. Reconstr. Surg. 105, 2500-2512. doi:10.1097/00006534-200006000-00032

Kim, J., and Bae, J.-S. (2016). Tumor-Associated Macrophages and Neutrophils in Tumor Microenvironment. Mediators Inflamm. 2016, 1-11. doi:10.1155/2016/ 6058147

Kim, M.-G., Kim, S. C., Ko, Y. S., Lee, H. Y., Jo, S.-K., and Cho, W. (2015). The Role of M2 Macrophages in the Progression of Chronic Kidney Disease Following Acute Kidney Injury. PLoS One 10, e0143961. doi:10.1371/ journal.pone. 0143961

Kim, S. Y., and Nair, M. G. (2019). Macrophages in Wound Healing: Activation and Plasticity. Immunol. Cel Biol 97, 258-267. doi:10.1111/imcb.12236

Kloc, M., Ghobrial, R. M., Wosik, J., Lewicka, A., Lewicki, S., and Kubiak, J. Z. (2019). Macrophage Functions in Wound Healing. J. Tissue Eng. Regen. Med. 13, 99-109. doi:10.1002/term.2772

Kniazeva, E., and Putnam, A. J. (2009). Endothelial Cell Traction and ECM Density Influence Both Capillary Morphogenesis and Maintenance in 3-D. Am. J. Physiology-Cell Physiol. 297, C179-C187. doi:10.1152/ ajpcell.00018.2009

Kobayashi, M., Kadota, J., Hashimoto, Y., Fujisato, T., Nakamura, N., Kimura, T., et al. (2020). Elastic Modulus of ECM Hydrogels Derived from Decellularized Tissue Affects Capillary Network Formation in Endothelial Cells. Ijms 21, 6304. doi:10.3390/ijms21176304

Koh, T. J., and Dipietro, L. A. (2011). Inflammation and Wound Healing: the Role of the Macrophage. Expert Rev. Mol. Med. 13, e23. doi:10.1017/ S1462399411001943

Kokai, L. E., Schilling, B. K., Chnari, E., Huang, Y.-C., Imming, E. A., Karunamurthy, A., et al. (2019). Injectable Allograft Adipose Matrix Supports Adipogenic Tissue Remodeling in the Nude Mouse and Human. Plast. Reconstr. Surg. 143, 299e-309e. doi:10.1097/PRS.0000000000005269

Kølle, S. F., Fischer-Nielsen, A., Mathiasen, A. B., Elberg, J. J., Oliveri, R. S., Glovinski, P. V., et al. (2013). Enrichment of Autologous Fat Grafts with ExVivo Expanded Adipose Tissue-Derived Stem Cells for Graft Survival: a Randomised Placebo-Controlled Trial. Lancet 382, 1113-1120. doi:10.1016/ s0140-6736(13)61410-5

Kumar, D., Shankar, K., Patel, S., Gupta, A., Varshney, S., Gupta, S., et al. (2018). Chronic Hyperinsulinemia Promotes Meta-Inflammation and Extracellular Matrix Deposition in Adipose Tissue: Implications of Nitric Oxide. Mol. Cell Endocrinol. 477, 15-28. doi:10.1016/j.mce.2018.05.010

Lancerotto, L., Chin, M. S., Freniere, B., Lujan-Hernandez, J. R., Li, Q., Vasquez, A. V., et al. (2013). Mechanisms of Action of External Volume Expansion Devices. Plast. Reconstr. Surg. 132, 569-578. doi:10.1097/PRS.0b013e31829ace30
Lawler, H. M., Underkofler, C. M., Kern, P. A., Erickson, C., Bredbeck, B., and Rasouli, N. (2016). Adipose Tissue Hypoxia, Inflammation, and Fibrosis in Obese Insulin-Sensitive and Obese Insulin-Resistant Subjects. J. Clin. Endocrinol. Metab. 101, 1422-1428. doi:10.1210/jc.2015-4125

Lee, S. G., Kim, J. S., Kim, H.-J., Schlaepfer, D. D., Kim, I.-S., and Nam, J.-O. (2021). Endothelial Angiogenic Activity and Adipose Angiogenesis Is Controlled by Extracellular Matrix Protein TGFBI. Sci. Rep. 11, 9644. doi:10.1038/s41598021-88959-1

Lee, S. H., Park, H. S., Lee, J. A., Song, Y. S., Jang, Y. J., Kim, J.-H., et al. (2013). Fibronectin Gene Expression in Human Adipose Tissue and its Associations with Obesity-Related Genes and Metabolic Parameters. Obes. Surg. 23, 554-560. doi:10.1007/s11695-012-0801-2

Lee, Y. S., Kim, J.-w., Osborne, O., Oh, D. Y., Sasik, R., Schenk, S., et al. (2014). Increased Adipocyte O2 Consumption Triggers HIF-1a, Causing Inflammation and Insulin Resistance in Obesity. Cell 157, 1339-1352. doi:10.1016/ j.cell.2014.05.012

Lehman, H. K., and Segal, B. H. (2020). The Role of Neutrophils in Host Defense and Disease. J. Allergy Clin. Immunol. 145, 1535-1544. doi:10.1016/ j.jaci.2020.02.038

Li, X., Zhao, Y., Chen, C., Yang, L., Lee, H.-h., Wang, Z., et al. (2020). Critical Role of Matrix Metalloproteinase 14 in Adipose Tissue Remodeling during Obesity. Mol. Cel Biol 40. doi:10.1128/MCB.00564-19

Li, Y., Wu, M., Zhang, Z., Xia, J., Wang, Z., Chen, X., et al. (2019). Application of External Force Regulates the Migration and Differentiation of Adipose-Derived Stem/Progenitor Cells by Altering Tissue Stiffness. Tissue Eng. Part A 25, 1614-1622. doi:10.1089/ten.TEA.2019.0046

Liao, X., Sharma, N., Kapadia, F., Zhou, G., Lu, Y., Hong, H., et al. (2011). Krüppellike Factor 4 Regulates Macrophage Polarization. J. Clin. Invest. 121, 2736-2749. doi:10.1172/JCI45444

Lin, D., Chun, T.-H., and Kang, L. (2016). Adipose Extracellular Matrix Remodelling in Obesity and Insulin Resistance. Biochem. Pharmacol. 119, 8-16. doi:10.1016/j.bcp.2016.05.005

Lin, S., Zhang, Q., Shao, X., Zhang, T., Xue, C., Shi, S., et al. (2017). IGF-1 Promotes Angiogenesis in Endothelial Cells/adipose-Derived Stem Cells Co-culture System with Activation of PI3K/Akt Signal Pathway. Cell Prolif 50, e12390. doi:10.1111/cpr.12390

Liu, K., Cai, J., Li, H., Feng, J., Feng, C., and Lu, F. (2018a). The Disturbed Function of Neutrophils at the Early Stage of Fat Grafting Impairs Long-Term Fat Graft Retention. Plast. Reconstr. Surg. 142, 1229-1238. doi:10.1097/ prs. 0000000000004882

Liu, X., Long, X., Gao, Y., Liu, W., Hayashi, T., Mizuno, K., et al. (2020). Type I Collagen Inhibits Adipogenic Differentiation via YAP Activation In Vitro. J. Cel Physiol 235, 1821-1837. doi:10.1002/jcp.29100

Liu, X., Long, X., Liu, W., Zhao, Y., Hayashi, T., Yamato, M., et al. (2018b). Type I Collagen Induces Mesenchymal Cell Differentiation into Myofibroblasts through YAP-Induced TGF-B1 Activation. Biochimie 150, 110-130. doi:10.1016/j.biochi.2018.05.005

Lu, P., Takai, K., Weaver, V. M., and Werb, Z. (2011). Extracellular Matrix Degradation and Remodeling in Development and Disease. Cold Spring Harbor Perspect. Biol. 3, a005058. doi:10.1101/cshperspect.a005058

Luo, T., Nocon, A., Fry, J., Sherban, A., Rui, X., Jiang, B., et al. (2016). AMPK Activation by Metformin Suppresses Abnormal Extracellular Matrix Remodeling in Adipose Tissue and Ameliorates Insulin Resistance in Obesity. Diabetes 65, 2295-2310. doi:10.2337/db15-1122

Maquoi, E., Munaut, C., Colige, A., Collen, D., and Lijnen, H. R. (2002). Modulation of Adipose Tissue Expression of Murine Matrix Metalloproteinases and Their Tissue Inhibitors with Obesity. Diabetes 51, 1093-1101. doi:10.2337/diabetes.51.4.1093

Marcelin, G., Ferreira, A., Liu, Y., Atlan, M., Aron-Wisnewsky, J., Pelloux, V., et al. (2017). A PDGFR $\alpha$-Mediated Switch toward CD9 High Adipocyte Progenitors Controls Obesity-Induced Adipose Tissue Fibrosis. Cel Metab. 25, 673-685. doi:10.1016/j.cmet.2017.01.010

Mariman, E. C. M., and Wang, P. (2010). Adipocyte Extracellular Matrix Composition, Dynamics and Role in Obesity. Cell. Mol. Life Sci. 67, 1277-1292. doi:10.1007/s00018-010-0263-4

Marks, P. W., Witten, C. M., and Califf, R. M. (2017). Clarifying Stem-Cell Therapy's Benefits and Risks. N. Engl. J. Med. 376, 1007-1009. doi:10.1056/ NEJMp1613723 
Mckee, T. J., Perlman, G., Morris, M., and Komarova, S. V. (2019). Extracellular Matrix Composition of Connective Tissues: a Systematic Review and MetaAnalysis. Sci. Rep. 9, 10542. doi:10.1038/s41598-019-46896-0

Mecham, R. P. (1998). Overview of Extracellular Matrix. Curr. Protoc. Cel Biol. doi:10.1002/0471143030.cb1001s00

Miksztowicz, V., Morales, C., Barchuk, M., López, G., Póveda, R., Gelpi, R., et al. (2017). Metalloproteinase 2 and 9 Activity Increase in Epicardial Adipose Tissue of Patients with Coronary Artery Disease. Cvp 15, 135-143. doi:10.2174/ 1570161114666161024124244

Mineda, K., Kuno, S., Kato, H., Kinoshita, K., Doi, K., Hashimoto, I., et al. (2014). Chronic Inflammation and Progressive Calcification as a Result of Fat Necrosis. Plast. Reconstr. Surg. 133, 1064-1072. doi:10.1097/PRS.0000000000000097

Mongiat, M., Andreuzzi, E., Tarticchio, G., and Paulitti, A. (2016). Extracellular Matrix, a Hard Player in Angiogenesis. Ijms 17, 1822. doi:10.3390/ ijms17111822

Mor-Yossef Moldovan, L., Lustig, M., Naftaly, A., Mardamshina, M., Geiger, T., Gefen, A., et al. (2019). Cell Shape Alteration during Adipogenesis Is Associated with Coordinated Matrix Cues. J. Cel Physiol 234, 3850-3863. doi:10.1002/ jcp. 27157

Mori, S., Kiuchi, S., Ouchi, A., Hase, T., and Murase, T. (2014). Characteristic Expression of Extracellular Matrix in Subcutaneous Adipose Tissue Development and Adipogenesis; Comparison with Visceral Adipose Tissue. Int. J. Biol. Sci. 10, 825-833. doi:10.7150/ijbs.8672

Morissette Martin, P., Shridhar, A., Yu, C., Brown, C., and Flynn, L. E. (2018). Decellularized Adipose Tissue Scaffolds for Soft Tissue Regeneration and Adipose-Derived Stem/Stromal Cell Delivery. Methods Mol. Biol. 1773, 53-71. doi:10.1007/978-1-4939-7799-4_6

Motz, K., Lina, I., Murphy, M. K., Drake, V., Davis, R., Tsai, H. W., et al. (2021). M2 Macrophages Promote Collagen Expression and Synthesis in Laryngotracheal Stenosis Fibroblasts. The Laryngoscope 131, E346-e353. doi:10.1002/lary.28980

Mouw, J. K., Ou, G., and Weaver, V. M. (2014). Extracellular Matrix Assembly: a Multiscale Deconstruction. Nat. Rev. Mol. Cel Biol 15, 771-785. doi:10.1038/ nrm3902

Murphy, G. (2011). Tissue Inhibitors of Metalloproteinases. Genome Biol. 12, 233. doi:10.1186/gb-2011-12-11-233

Nacu, N., Luzina, I. G., Highsmith, K., Lockatell, V., Pochetuhen, K., Cooper, Z. A., et al. (2008). Macrophages Produce TGF- $\beta$-Induced ( $\beta$-Ig-H3) Following Ingestion of Apoptotic Cells and Regulate MMP14 Levels and Collagen Turnover in Fibroblasts. J. Immunol. 180, 5036-5044. doi:10.4049/ jimmunol.180.7.5036

Nakajima, I., Muroya, S., Tanabe, R.-I., and Chikuni, K. (2002). Extracellular Matrix Development during Differentiation into Adipocytes with a Unique Increase in Type V and VI Collagen. Biol. Cel 94, 197-203. doi:10.1016/s02484900(02)01189-9

Nissinen, L. M., and Kähäri, V.-M. (2015). Collagen Turnover in Wound Repair--A Macrophage Connection. J. Invest. Dermatol. 135, 2350-2352. doi:10.1038/ jid.2015.246

Ørholt, M., Larsen, A., Hemmingsen, M. N., Mirian, C., Zocchi, M. L., VesterGlowinski, P. V., et al. (2020). Complications after Breast Augmentation with Fat Grafting: A Systematic Review. Plast. Reconstr. Surg. 145, 530e-537e. doi:10.1097/PRS.0000000000006569

O’Rourke, R. W., White, A. E., Metcalf, M. D., Olivas, A. S., Mitra, P., Larison, W. G., et al. (2011). Hypoxia-induced Inflammatory Cytokine Secretion in Human Adipose Tissue Stromovascular Cells. Diabetologia 54, 1480-1490. doi:10.1007/ s00125-011-2103-y

Pang, X., Zhang, Y., Shi, X., Peng, Z., Xing, Y., and Jiarui, H. (2020). Hirudin Reduces the Expression of Markers of the Extracellular Matrix in Renal Tubular Epithelial Cells in a Rat Model of Diabetic Kidney Disease through the Hypoxia-Inducible Factor-1 $\alpha$ (HIF-1 $\alpha$ )/Vascular Endothelial Growth Factor (VEGF) Signaling Pathway. Med. Sci. Monit. 26, e921894. doi:10.12659/ MSM.921894

Park, J., and Scherer, P. E. (2012). Adipocyte-derived Endotrophin Promotes Malignant Tumor Progression. J. Clin. Invest. 122, 4243-4256. doi:10.1172/ JCI63930

Pasarica, M., Sereda, O. R., Redman, L. M., Albarado, D. C., Hymel, D. T., Roan, L. E., et al. (2009). Reduced Adipose Tissue Oxygenation in Human Obesity: Evidence for Rarefaction, Macrophage Chemotaxis, and Inflammation without an Angiogenic Response. Diabetes 58, 718-725. doi:10.2337/db08-1098
Petäistö, T., Vicente, D., Mäkelä, K. A., Finnilä, M. A., Miinalainen, I., Koivunen, J., et al. (2020). Lack of Collagen XVIII Leads to Lipodystrophy and Perturbs Hepatic Glucose and Lipid Homeostasis. J. Physiol. 598, 3373-3393. doi:10.1113/JP279559

Peurichard, D., Ousset, M., Paupert, J., Aymard, B., Lorsignol, A., Casteilla, L., et al. (2019). Extra-cellular Matrix Rigidity May Dictate the Fate of Injury Outcome. J. Theor. Biol. 469, 127-136. doi:10.1016/j.jtbi.2019.02.017

Pham, C. T. N. (2006). Neutrophil Serine Proteases: Specific Regulators of Inflammation. Nat. Rev. Immunol. 6, 541-550. doi:10.1038/nri1841

Phipps, K. D., Gebremeskel, S., Gillis, J., Hong, P., Johnston, B., and Bezuhly, M. (2015). Alternatively Activated M2 Macrophages Improve Autologous Fat Graft Survival in a Mouse Model through Induction of Angiogenesis. Plast. Reconstr. Surg. 135, 140-149. doi:10.1097/PRS.0000000000000793

Plaks, V., Kong, N., and Werb, Z. (2015). The Cancer Stem Cell Niche: How Essential Is the Niche in Regulating Stemness of Tumor Cells? Cell Stem Cell 16, 225-238. doi:10.1016/j.stem.2015.02.015

Plikus, M. V., Guerrero-Juarez, C. F., Ito, M., Li, Y. R., Dedhia, P. H., Zheng, Y., et al. (2017). Regeneration of Fat Cells from Myofibroblasts during Wound Healing. Science 355, 748-752. doi:10.1126/science.aai8792

Pope, B. D., Warren, C. R., Parker, K. K., and Cowan, C. A. (2016). Microenvironmental Control of Adipocyte Fate and Function. Trends Cel Biol. 26, 745-755. doi:10.1016/j.tcb.2016.05.005

Pu, L. L. Q. (2012). Discussion. Plast. Reconstr. Surg. 129, 1093-1095. doi:10.1097/ PRS.0b013e31824a2b4b

Qiu, L., Su, Y., Zhang, D., Song, Y., Liu, B., Yu, Z., et al. (2016). Identification of the Centrifuged Lipoaspirate Fractions Suitable for Postgrafting Survival. Plast. Reconstr. Surg. 137, 67e-76e. doi:10.1097/PRS.0000000000001883

Radisky, D. C., Kenny, P. A., and Bissell, M. J. (2007). Fibrosis and Cancer: Do Myofibroblasts Come Also from Epithelial Cells via EMT? J. Cel. Biochem. 101, 830-839. doi:10.1002/jcb.21186

Rankin, E. B., Biju, M. P., Liu, Q., Unger, T. L., Rha, J., Johnson, R. S., et al. (2007). Hypoxia-inducible Factor-2 (HIF-2) Regulates Hepatic Erythropoietin In Vivo. J. Clin. Invest. 117, 1068-1077. doi:10.1172/JCI30117

Riis, S., Stensballe, A., Emmersen, J., Pennisi, C. P., Birkelund, S., Zachar, V., et al. (2016). Mass Spectrometry Analysis of Adipose-Derived Stem Cells Reveals a Significant Effect of Hypoxia on Pathways Regulating Extracellular Matrix. Stem Cel Res Ther 7. doi:10.1186/s13287-016-0310-7

Roh, D. S., and Orgill, D. P. (2018). Discussion. Plast. Reconstr. Surg. 141, 387-388. doi:10.1097/PRS.0000000000004029

Rosell-García, T., Palomo-Álvarez, O., and Rodríguez-Pascual, F. (2019). A Hierarchical Network of Hypoxia-Inducible Factor and SMAD Proteins Governs Procollagen Lysyl Hydroxylase 2 Induction by Hypoxia and Transforming Growth Factor $\beta 1$. J. Biol. Chem. 294, 14308-14318. doi:10.1074/jbc.RA119.007674

Rozario, T., and Desimone, D. W. (2010). The Extracellular Matrix in Development and Morphogenesis: a Dynamic View. Dev. Biol. 341, 126-140. doi:10.1016/ j.ydbio.2009.10.026

Ruan, Q. Z., Rinkinen, J. R., Doval, A. F., Scott, B. B., Tobias, A. M., Lin, S. J., et al. (2019). Safety Profiles of Fat Processing Techniques in Autologous Fat Transfer for Breast Reconstruction. Plast. Reconstr. Surg. 143, 985-991. doi:10.1097/ PRS.0000000000005424

Ruiz-Ojeda, F. J., Méndez-Gutiérrez, A., Aguilera, C. M., and Plaza-Díaz, J. (2019). Extracellular Matrix Remodeling of Adipose Tissue in Obesity and Metabolic Diseases. Ijms 20, 4888. doi:10.3390/ijms20194888

Sadik, C. D., Kim, N. D., and Luster, A. D. (2011). Neutrophils Cascading Their Way to Inflammation. Trends Immunol. 32, 452-460. doi:10.1016/ j.it.2011.06.008

Saunders, C. J., Van Der Merwe, L., Cook, J., Handley, C. J., Collins, M., and September, A. V. (2015). Extracellular Matrix Proteins Interact with CellSignaling Pathways in Modifying Risk of Achilles Tendinopathy. J. Orthop. Res. 33, 898-903. doi:10.1002/jor.22820

Schipper, H. S., Prakken, B., Kalkhoven, E., and Boes, M. (2012). Adipose TissueResident Immune Cells: Key Players in Immunometabolism. Trends Endocrinol. Metab. 23, 407-415. doi:10.1016/j.tem.2012.05.011

Schnoor, M., Cullen, P., Lorkowski, J., Stolle, K., Robenek, H., Troyer, D., et al. (2008). Production of Type VI Collagen by Human Macrophages: a New Dimension in Macrophage Functional Heterogeneity. J. Immunol. 180, 5707-5719. doi:10.4049/jimmunol.180.8.5707 
Seaman, S. A., Cao, Y., Campbell, C. A., and Peirce, S. M. (2016). Macrophage Recruitment and Polarization during Collateral Vessel Remodeling in Murine Adipose Tissue. Microcirculation 23, 75-87. doi:10.1111/micc.12261

Shida, M., Chiba, A., Ohashi, M., and Yamakawa, M. (2017). Ultrasound Diagnosis and Treatment of Breast Lumps after Breast Augmentation with Autologous Fat Grafting. Plast. Reconstr. Surg. - Glob. Open 5, e1603. doi:10.1097/ GOX.0000000000001603

Shook, B. A., Wasko, R. R., Rivera-Gonzalez, G. C., Salazar-Gatzimas, E., LópezGiráldez, F., Dash, B. C., et al. (2018). Myofibroblast Proliferation and Heterogeneity Are Supported by Macrophages during Skin Repair. Science 362. doi:10.1126/science.aar2971

Shook, B., and Rodeheffer, M. S. (2017). Forecasting Fat Fibrosis. Cel Metab. 25, 493-494. doi:10.1016/j.cmet.2017.02.019

Siegel-Axel, D. I., Ullrich, S., Stefan, N., Rittig, K., Gerst, F., Klingler, C., et al. (2014). Fetuin-A Influences Vascular Cell Growth and Production of Proinflammatory and Angiogenic Proteins by Human Perivascular Fat Cells. Diabetologia 57, 1057-1066. doi:10.1007/s00125-014-3177-0

Skuli, N., Liu, L., Runge, A., Wang, T., Yuan, L., Patel, S., et al. (2009). Endothelial Deletion of Hypoxia-Inducible Factor-2 $\alpha$ (HIF-2 $\alpha$ ) Alters Vascular Function and Tumor Angiogenesis. Blood 114, 469-477. doi:10.1182/blood-2008-12193581

Sorisky, A., Molgat, A. S. D., and Gagnon, A. (2013). Macrophage-induced Adipose Tissue Dysfunction and the Preadipocyte: Should I Stay (And Differentiate) or Should I Go? Adv. Nutr. 4, 67-75. doi:10.3945/an.112.003020

Soucy, P. A., and Romer, L. H. (2009). Endothelial Cell Adhesion, Signaling, and Morphogenesis in Fibroblast-Derived Matrix. Matrix Biol. 28, 273-283. doi:10.1016/j.matbio.2009.04.005

Soulez, M., Sirois, I., Brassard, N., Raymond, M.-A., Nicodème, F., Noiseux, N., et al. (2010). Epidermal Growth Factor and Perlecan Fragments Produced by Apoptotic Endothelial Cells Co-ordinately Activate ERK1/2-dependent Antiapoptotic Pathways in Mesenchymal Stem Cells. Stem Cells 28, 810-820. doi:10.1002/stem.403

Souza, L. R., Silva, E., Calloway, E., Cabrera, C., and Mclemore, M. L. (2013). G-CSF Activation of AKT Is Not Sufficient to Prolong Neutrophil Survival. J. Leukoc. Biol. 93, 883-893. doi:10.1189/jlb.1211591

Spear, S. L., Coles, C. N., Leung, B. K., Gitlin, M., Parekh, M., and Macarios, D. (2016). The Safety, Effectiveness, and Efficiency of Autologous Fat Grafting in Breast Surgery. Plast. Reconstr. Surg. - Glob. Open 4, e827. doi:10.1097/ GOX.0000000000000842

Spencer, M., Yao-Borengasser, A., Unal, R., Rasouli, N., Gurley, C. M., Zhu, B., et al. (2010). Adipose Tissue Macrophages in Insulin-Resistant Subjects Are Associated with Collagen VI and Fibrosis and Demonstrate Alternative Activation. Am. J. Physiology-Endocrinology Metab. 299, E1016-E1027. doi:10.1152/ajpendo.00329.2010

Stamenkovic, I. (2003). Extracellular Matrix Remodelling: the Role of Matrix Metalloproteinases. J. Pathol. 200, 448-464. doi:10.1002/path.1400

Steinbrech, D. S., Longaker, M. T., Mehrara, B. J., Saadeh, P. B., Chin, G. S., Gerrets, R. P., et al. (1999). Fibroblast Response to Hypoxia: the Relationship between Angiogenesis and Matrix Regulation. J. Surg. Res. 84, 127-133. doi:10.1006/ jsre.1999.5627

Sternlicht, M. D., and Werb, Z. (2001). How Matrix Metalloproteinases Regulate Cell Behavior. Annu. Rev. Cel Dev. Biol. 17, 463-516. doi:10.1146/ annurev.cellbio.17.1.463

Streuli, C. (1999). Extracellular Matrix Remodelling and Cellular Differentiation. Curr. Opin. Cel Biol. 11, 634-640. doi:10.1016/s0955-0674(99)00026-5

Strong, A. L., Cederna, P. S., Rubin, J. P., Coleman, S. R., and Levi, B. (2015). The Current State of Fat Grafting. Plast. Reconstr. Surg. 136, 897-912. doi:10.1097/ PRS.0000000000001590

Suga, H., Eto, H., Aoi, N., Kato, H., Araki, J., Doi, K., et al. (2010). Adipose Tissue Remodeling under Ischemia: Death of Adipocytes and Activation of Stem/ progenitor Cells. Plast. Reconstr. Surg. 126, 1911-1923. doi:10.1097/ PRS.0b013e3181f4468b

Sun, K., Tordjman, J., Clément, K., and Scherer, P. E. (2013). Fibrosis and Adipose Tissue Dysfunction. Cel Metab. 18, 470-477. doi:10.1016/j.cmet.2013.06.016

Tassinari, J., Sisti, A., Zerini, I., Idone, F., and Nisi, G. (2016). Oil Cysts after Breast Augmentation with Autologous Fat Grafting. Plast. Reconstr. Surg. 137, 244e-245e. doi:10.1097/PRS.0000000000001914
Tazzyman, S., Niaz, H., and Murdoch, C. (2013). Neutrophil-mediated Tumour Angiogenesis: Subversion of Immune Responses to Promote Tumour Growth. Semin. Cancer Biol. 23, 149-158. doi:10.1016/j.semcancer.2013.02.003

Theocharidis, G., Drymoussi, Z., Kao, A. P., Barber, A. H., Lee, D. A., Braun, K. M., et al. (2016). Type VI Collagen Regulates Dermal Matrix Assembly and Fibroblast Motility. J. Invest. Dermatol. 136, 74-83. doi:10.1038/JID.2015.352

Trayhurn, P. (2014). Hypoxia and Adipocyte Physiology: Implications for Adipose Tissue Dysfunction in Obesity. Annu. Rev. Nutr. 34, 207-236. doi:10.1146/ annurev-nutr-071812-161156

Vaicik, M. K., Thyboll Kortesmaa, J., Movérare-Skrtic, S., Kortesmaa, J., Soininen, R., Bergström, G., et al. (2014). Laminin a4 Deficient Mice Exhibit Decreased Capacity for Adipose Tissue Expansion and Weight Gain. PLoS One 9, e109854. doi:10.1371/journal.pone.0109854

Van Der Donckt, C., Van Herck, J. L., Schrijvers, D. M., Vanhoutte, G., Verhoye, M., Blockx, I., et al. (2015). Elastin Fragmentation in Atherosclerotic Mice Leads to Intraplaque Neovascularization, Plaque Rupture, Myocardial Infarction, Stroke, and Sudden Death. Eur. Heart J. 36, 1049-1058. doi:10.1093/ eurheartj/ehu041

Villesen, I. F., Daniels, S. J., Leeming, D. J., Karsdal, M. A., and Nielsen, M. J. (2020). Review Article: the Signalling and Functional Role of the Extracellular Matrix in the Development of Liver Fibrosis. Aliment. Pharmacol. Ther. 52, 85-97. doi:10.1111/apt.15773

Wang, X., Wang, Y., Bosshardt, D. D., Miron, R. J., and Zhang, Y. (2018). The Role of Macrophage Polarization on Fibroblast Behavior-An In Vitro Investigation on Titanium Surfaces. Clin. Oral Invest. 22, 847-857. doi:10.1007/s00784-0172161-8

Wang, Z., Chen, Y., Zhu, S., Chen, X., Guan, J., Yao, Y., et al. (2020). The Effects of Macrophage-mediated Inflammatory Response to the Donor Site on Long-term Retention of a Fat Graft in the Recipient Site in a Mice Model. J. Cel Physiol 235, 10012-10023. doi:10.1002/jcp. 29816

Werner, S., and Grose, R. (2003). Regulation of Wound Healing by Growth Factors and Cytokines. Physiol. Rev. 83, 835-870. doi:10.1152/physrev.2003.83.3.835

Wick, G., Grundtman, C., Mayerl, C., Wimpissinger, T.-F., Feichtinger, J., Zelger, B., et al. (2013). The Immunology of Fibrosis. Annu. Rev. Immunol. 31, 107-135. doi:10.1146/annurev-immunol-032712-095937

Wilgus, T. A., Roy, S., and Mcdaniel, J. C. (2013). Neutrophils and Wound Repair: Positive Actions and Negative Reactions. Adv. Wound Care 2, 379-388. doi:10.1089/wound.2012.0383

Worthen, C. A., Cui, Y., Orringer, J. S., Johnson, T. M., Voorhees, J. J., and Fisher, G. J. (2020). CD26 Identifies a Subpopulation of Fibroblasts that Produce the Majority of Collagen during Wound Healing in Human Skin. J. Invest. Dermatol. 140, 2515-2524. doi:10.1016/j.jid.2020.04.010

Xu, Q., Liu, X., Liu, W., Hayashi, T., Yamato, M., Fujisaki, H., et al. (2019). Type I Collagen-Induced YAP Nuclear Expression Promotes Primary Cilia Growth and Contributes to Cell Migration in Confluent Mouse Embryo Fibroblast 3T3L1 Cells. Mol. Cel Biochem 450, 87-96. doi:10.1007/s11010-018-3375-z

Yoshimura, K., Asano, Y., Aoi, N., Kurita, M., Oshima, Y., Sato, K., et al. (2010). Progenitor-enriched Adipose Tissue Transplantation as rescue for Breast Implant Complications. Breast J. 16, 169-175. doi:10.1111/j.15244741.2009.00873.x

Yoshimura, K., Eto, H., Kato, H., Doi, K., and Aoi, N. (2011). In Vivo manipulation of Stem Cells for Adipose Tissue Repair/reconstruction. Regenerative Med. 6, 33-41. doi:10.2217/rme.11.62

Yoshimura, K., Sato, K., Aoi, N., Kurita, M., Hirohi, T., and Harii, K. (2020). CellAssisted Lipotransfer for Cosmetic Breast Augmentation: Supportive Use of Adipose-Derived Stem/Stromal Cells. Aesth Plast. Surg. 44, 1258-1265. doi:10.1007/s00266-020-01819-7

Yoshimura, K., Sato, K., Aoi, N., Kurita, M., Inoue, K., Suga, H., et al. (2008). Cellassisted Lipotransfer for Facial Lipoatrophy: Efficacy of Clinical Use of Adipose-Derived Stem Cells. Dermatol. Surg. 34, 1178-1185. doi:10.1111/ j.1524-4725.2008.34256.x

Yu, N.-Z., Huang, J.-Z., Zhang, H., Wang, Y., Wang, X.-J., Zhao, R., et al. (2015). A Systemic Review of Autologous Fat Grafting Survival Rate and Related Severe Complications. Chin. Med. J. (Engl) 128, 1245-1251. doi:10.4103/03666999.156142

Zhang, X., Lam, K. S. L., Ye, H., Chung, S. K., Zhou, M., Wang, Y., et al. (2010). Adipose Tissue-specific Inhibition of Hypoxia-Inducible Factor 1a Induces 
Obesity and Glucose Intolerance by Impeding Energy Expenditure in Mice*. J. Biol. Chem. 285, 32869-32877. doi:10.1074/jbc.M110.135509

Zhang, Z., Cai, J., Li, Y., He, Y., Dong, Z., Dai, J., et al. (2020). External Volume Expansion Adjusted Adipose Stem Cell by Shifting the Ratio of Fibronectin to Laminin. Tissue Eng. Part A 26, 66-77. doi:10.1089/ ten.TEA.2019.0095

Zhang, Z., Qu, R., Fan, T., Ouyang, J., Lu, F., and Dai, J. (2019). Stepwise Adipogenesis of Decellularized Cellular Extracellular Matrix Regulates Adipose Tissue-Derived Stem Cell Migration and Differentiation. Stem Cell Int. 2019, 1-11. doi:10.1155/2019/1845926

Zhao, Y., Gu, X., Zhang, N., Kolonin, M. G., An, Z., and Sun, K. (2016). Divergent Functions of Endotrophin on Different Cell Populations in Adipose Tissue. Am. J. Physiology-Endocrinology Metab. 311, E952-e963. doi:10.1152/ ajpendo.00314.2016

Zhou, Z. Q., Chen, Y., Chai, M., Tao, R., Lei, Y. H., Jia, Y. Q., et al. (2018). Adipose Extracellular Matrix Promotes Skin Wound Healing by Inducing the Differentiation of Adipose-derived S-tem C-ells into F-ibroblasts. Int. J. Mol. Med. doi:10.3892/ijmm.2018.4006

Zhu, Y., Liao, Y., Zhang, Y., Shekh, M. I., Zhang, J., You, Z., et al. (2021). Novel Nanofibrous Membrane-supporting Stem Cell Sheets for Plasmid Delivery and
Cell Activation to Accelerate Wound Healing. Bioeng. Transl Med. doi:10.1002/ btm2.10244

Conflict of Interest: The authors declare that the research was conducted in the absence of any commercial or financial relationships that could be construed as a potential conflict of interest.

Publisher's Note: All claims expressed in this article are solely those of the authors and do not necessarily represent those of their affiliated organizations, or those of the publisher, the editors and the reviewers. Any product that may be evaluated in this article, or claim that may be made by its manufacturer, is not guaranteed or endorsed by the publisher.

Copyright (c) $2021 \mathrm{Bi}, \mathrm{Li}$, Dong, Zhao, Wu, Zou, Guo, Lu and Gao. This is an openaccess article distributed under the terms of the Creative Commons Attribution License (CC BY). The use, distribution or reproduction in other forums is permitted, provided the original author(s) and the copyright owner(s) are credited and that the original publication in this journal is cited, in accordance with accepted academic practice. No use, distribution or reproduction is permitted which does not comply with these terms. 